\title{
More Dynamic Than You Think: Hidden Aspects of Decision-Making
}

\author{
Jennifer Robinson ${ }^{1}$, Marta Sinclair ${ }^{2}$, Jutta Tobias ${ }^{1, *}$ and Ellen Choi ${ }^{3}$ \\ 1 School of Management, Cranfield University, Cranfield MK43 0AL, UK; \\ jennifer-llewellen.robinson@cranfield.ac.uk \\ 2 Department of International Business and Asian Studies, Griffith University, Nathan QLD 4111, Australia; \\ m.sinclair@griffith.edu.au \\ 3 Ivey Business School, Western University, ON N6G 0N1, Canada; echoi.phd@ivey.ca \\ * Correspondence: jutta.tobias@cranfield.ac.uk
}

Received: 21 November 2016; Accepted: 8 July 2017; Published: 14 July 2017

\begin{abstract}
Decision-making is a multifaceted, socially constructed, human activity that is often non-rational and non-linear. Although the decision-making literature has begun to recognize the effect of affect on decisions, examining for example the contribution of bodily sensations to affect, it continues to treat the various processes involved in coming to a decision as compartmentalized and static. In this paper, we use five theories to contribute to our understanding of decision-making, and demonstrate that it is much more fluid, multi-layered and non-linear than previously acknowledged. Drawing on a group experience of deciding, we investigate the intrapersonal, interpersonal, and collective states that are at play. These states are shown to be iterative: each being reinforced or dampened in a complex interaction of thought, affect, social space and somatic sensations in a dynamic flux, whilst individuals try to coalesce on a decision. This empirical investigation contributes to theory, method and practice by suggesting that Volatility, Uncertainty, Complexity and Ambiguity (VUCA) is a human condition. VUCA permeates and impacts decision-making in a multitude of ways, beyond researchers' previous understanding. The innovation generated through this paper resides in a set of propositions that will accelerate progress in the theory, method, and practice of decision-making.
\end{abstract}

Keywords: non-rational; decision-making; intuition; mindfulness; wisdom; organizational space; social improvising

\section{Introduction}

Decisions-even strategic decisions-are increasingly made within a context that can be characterized as time-pressured, dynamic, uncertain, and with decision makers having access to inadequate information. In some instances, the situation is so new that there is little or no historical data available. In other cases, there are vast volumes of information but not enough time to process it. In short, we live in a VUCA world. The term "VUCA" has its genesis back at the end of the Cold War and was originally coined to ring in an era marked by increasingly ambiguous, multilateral, and multifaceted challenges in conditions that are Volatile, Uncertain, Complex, and Ambiguous (VUCA) (Hicks and Nicholas 2002). Seminal papers such as that by Allison (Allison 1969) demonstrate VUCA in action; in particular, the way that many constituent parts combine to create unique contexts at unique time points, unique decisions, and unique consequences. VUCA means that never-to-be repeated conditions provide the background against which decisions get made. This point is further illustrated by recent events in the world around us. During the writing of this paper, geopolitical shifts such as Brexit in the United Kingdom and the election of President Donald Trump seem to indicate that assumptions deemed immutable are less solid than 
they appear (https://extranet.cranfield.ac.uk/dana-na/auth/url_default/welcome.cgi). The macro environment of decisions for politicians is substantively different and evolving faster than, for example, just 12 months ago. This is not just true in politics but in many arenas including business, where scandals continue to emerge based on the actions of a very few. In a tightly coupled world, each action has consequential actions and counter actions (Weick and Roberts 1993) triggering further actions and counter actions, many of which are unpredictable.

This is how VUCA has become the reality that many senior executives in organizations routinely face when making decisions, operational as well as strategic. Given the fluidity of situations, and that facts too, can be emergent, decision-making theory and practice cannot be overly mechanistic. Fluidity in this context is taken to mean a continuous flux, where "rapid, unpredictable change [occurs] in many directions" (Lane and Maznevski 2014, p. 14). This, in turn, requires continuous adjustments when making sense of a situation, rendering the decision-making process itself fluid. Within this context, new models of decision-making are needed to take account of new organizational realities.

To meet the challenges of the current reality, scholars have turned their attention to new perspectives that complement and enrich (not necessarily replace) the analytical, rational models of decision-making (Eisenhardt and Zbaracki 1992; Isenberg 1984; Klein 1998; Langley et al. 1995). These new perspectives are the focus of this paper. As traditional decision-making theory has been extensively discussed and researched elsewhere (Tversky and Kahneman 1985), the ensuing discussion foregrounds less explored, still developing approaches that might yield additional insights in an effort to bring contemporary decision-making perspectives into balance. This is not completely unexplored territory, following seminal work published, for example, by Dane and Pratt (2007) and Lieberman (2000) on intuition; Kabat-Zinn 2005 (2005) and Fiol and O'Connor (2003) on mindfulness; Lefebvre (1991) and Nonaka and Takeuchi (1991) on organizational space, and Weick (1998) on improvisation (Dane and Pratt 2007; Sadler-Smith 2016; Kabat-Zinn 2005; Fiol and O'Connor 2003; Lefebvre 1991; Nonaka and Takeuchi 1995; Weick 1998). These papers provide growing evidence that non-traditional perspectives have a contribution to make to theory building.

Herein we provide an integrative, iterative, and innovative perspective on decision-making, drawing on "non-rational" or "bottom up" frameworks such as mindfulness and intuition, some of which have been insufficiently integrated into the decision-making literature because they may defy strict "scientific" explanations (see for example, Dane and Pratt (2007)). By way of contrast, we contend that by explicitly addressing decision-making from a variety of perspectives, we can generate new insights that address the specific demands of a VUCA world, particularly with respect to decision-making. In doing so we propose ways that new perspectives can amend and/or complement traditional rational approaches. This move to consider non-rational decision-making is also mirrored in economics, where it is increasingly acknowledged that, for example, emotions have a role to play (Oullier and Basso 2010, p. 296).

In this paper, we have adopted a pluralistic approach that weaves together different perspectives without losing each theoretical contribution. Integration has not been achieved through an assimilative process but instead, a deliberate layering of diversity. Our approach aligns with the current scholarly narrative concerning the deepening of understanding of phenomena. Most particularly, the 2017 Academy of Management Annual Meeting is themed "At the Interface", which explicates the drive to consider "interstitial spaces", including those that lie within and between disciplines (http:/ /aom. org/annualmeeting/theme/). Further, the editorial for the Academy of Management Learning \& Education edition (2014) urges scholars to "cross-train" (Kenworthy 2014). In keeping with this new wave of enquiry, we have been careful not to reconcile different relationships but rather to lay concepts side-by-side and/or juxtapose each perspective as appropriate, thus creating space for multifaceted, contextual decision-making approaches. Based on themes emerging from theory and practice, we have considered five perspectives as a starting point: mindfulness, intuition, wisdom, organizational space, and social improvisation. The aim of this paper is to explore how each perspective contributes to and/or complements current decision-making practices. These perspectives have been recently 
explored as possible ways to address the VUCA conditions; however, to date each has been studied in isolation, thus further fragmenting (instead of integrating) contributions to the decision-making field. Although each perspective is rooted in a different philosophy and literature, all have attempted to address the fluid nature of contemporary decision-making, and acknowledge the role of awareness in the process. Our inclusive and non-hierarchical stance avoids a reductionist approach and holds all points of view to be equally valid. This pluralistic stance models both our methodology and our contribution to theory; it also has implications for practice.

In keeping with this investigative quality, our methodology is similarly pluralistic, seeking to bring "understanding rather than measurement" to the nature of decisions (Hernes 2007, p. 143). At the heart of this investigation was the design, delivery, and analysis of a workshop with like-minded academics and practitioners who critiqued our thinking and built upon it. This experience forms the basis for our findings. Approaching the research process as an unfolding (Hernes 2007), our research question was for guidance, not adherence-as follows: What hidden aspects of the decision-making process are revealed through a multiple-perspective approach? We begin this paper with a description of the five different perspectives on decision-making and highlight their unique contribution to the role of awareness and fluidity in the decision-making process. In drawing on these different views we seek to demonstrate the multi-level nature of decisions, particularly in organizations where strategic choices are rarely the purview of one individual but may involve many groups coming together to discuss and decide. The paper then illustrates an innovative and iterative approach to knowledge creation through the integration of these various facets of decision-making. It concludes with a discussion of the propositions we draw from analyzing the findings from the workshop experience, and suggestions for follow-up research.

\subsection{Mindfulness}

Mindfulness refers to present-moment, non-judgmental awareness of internal and external phenomena (Brown and Ryan 2003). A good portion of mindfulness research is concerned with the antecedents and consequences of consciously paying attention to the present moment thereby increasing awareness of the different perspectives and different interpretations that exist within any present moment experience. Mindfulness is a multi-level construct that can be practiced by individuals, for example through meditation, or induced at collective levels (for instance in teams or entire organizations) through non-meditative processes and routines (Sutcliffe et al. 2016). Mindfulness can equip individuals and groups with self and situational awareness and the ability to pause before reacting (Garland et al. 2011). This brief pause lends itself to a variety of improved outcomes including less bias and reliance on outmoded mental heuristics (Fiol and O'Connor 2003).

There is a growing body of empirical evidence that mindfulness promotes bottom-up and non-judgmental, or rather pre-judgmental, processing. In other words, experiencing the situations we encounter in a mindful way enables us to question or at least delay premature judgment. Indeed, recent mindfulness research examining individuals' decision-making has demonstrated that mindfulness may help people make more effective or even 'rational' decisions. A specific example of a mindfulness intervention is Hafenbrack, Kinias and Barsade's (Hafenbrack et al. 2013) research where just 15 minutes of mindfulness practice reliably enabled research participants to bypass the sunk cost bias. In terms of individual-level processes, mindfulness training has been linked reliably with increased cognitive skills, for example increased working memory (Mrazek et al. 2013), insight problem solving (Ostafin and Kassman 2012), creative performance (Baas et al. 2014) and several other different measures of intelligence.

Mostly, we believe our minds are open and objective like a court jury; however, without mindfulness, or a similar practice that develops an understanding of one's subjective experience, our minds may work more like lawyers, selectively choosing arguments and buying into facts that align with our internal and post hoc narratives (Haidt 2001). Our own research described herein demonstrates this lack of objectivity. Integrating the practices of mindfulness may offer tools to help 
us pause, and reflect when considering the decision criteria and broader scope of the situation while honouring the challenges of being human. This reflexivity offers a more objective quality of awareness and offers flexibility of position and perspective during a fluid decision-making process.

Mindfulness can be placed within the decision-making literature alongside perspectives that acknowledge the limitations of bounded rationality (March and Simon 1993) and human inference (Kahneman et al. 1982). One intention of mindfulness practices is to train what is referred to in the contemplative traditions as "bare attention" (Gunaratana 2009), a quality of attention that enables phenomenon to be absorbed without judgment, with limited influence of the past, and without immediate categorization into existing cognitive schemas. This characteristic of mindfulness supports equanimity and allows decision makers to treat equally information and data that are both confirmatory and dis-confirmatory of a preferred point of view (Santorelli 2011). This open approach to processing information is the antithesis of premature cognitive commitment (Langer 1992, p. 292). It provides an individual with the facility to be conscious of both the "content and context of information" (Sinclair and Ashkanasy 2005, p. 290) so that it becomes possible to use information outside of pre-established categories. Such freedom from cognitive rigidity can underpin novel idea generation such as seeing a chair for a ladder or a rubber dog toy as an eraser.

Mindfulness challenges paradigms of top-down management control thinking, and instead embraces bottom-up processing at different levels of analysis: internal, interpersonal, and collective (Sutcliffe et al. 2016). In sum, mindfulness brings light to a quality of attention that has gone relatively under examined in the extant decision-making models. As information is processed, not all of it will be interpreted equally since our prior experiences, habits and biases may color what information we notice and how we absorb it. Studying the mindful processing of information allows researchers to consider how such bottom-up, non- or pre-judgment related processes may prompt decision makers to break habitual, potentially less effective, decision-making patterns in a VUCA world.

\subsection{Intuition}

Intuition is understood as direct knowing without any use of conscious reasoning (Sinclair and Ashkanasy 2005). It refers to our ability to process subconsciously or access directly information without the engagement of rational thinking, be it in the form of analysis or development of a logical argument. We think of a problem or see a situation and simply know the answer, albeit we are not aware that any deliberation on our part occurred. That is why intuition is sometimes called 'knowing what without knowing how' (Vaughan 1979). Dual-process theories (Epstein 1990; Stanovich and West 2000) suggest that our brain activates different regions, for different reasons, and that various mental processes strengthen certain regions of the brain. For example, Lieberman and colleagues (Lieberman et al. 2007) demonstrated that asking participants to label their affective state activated the right pre-frontal cortex, thereby dampening the effect of the amygdala, or primitive brain. Desbordes et al. (2012) also found reduced activity in the amygdala within a mindfulness group of practitioners when compared to a control group. The mechanism that de-activates one part of the brain to activate another is still under investigation, but there is sufficient evidence to show that some of these functions are physiologically binary.

Whilst brain and mind are not synonymous (Sinclair 2016), for intuition, which is considered a more primitive evolutionary process, its neural network is often used as a default setting until or unless the situation calls for an intentional employment of reasoning faculty. This conclusion is supported by brain mapping studies that identified two distinct neural systems used for each type of information processing respectively (Lieberman et al. 2004). Lieberman (Lieberman 2007; Lieberman 2000) describes the neural network that is involved in controlled (i.e., conscious) information processing as reflective and the network that serves automatic (i.e., non-conscious) information processing as reflexive. In management terms, a common type of intuitive processing linked to expertise (expert intuition, see (Dane and Pratt 2007; Kahneman and Klein 2009)) as a form of fast non-conscious cognition is called System 1 while conscious, deliberate reasoning tends to be called System 2 (Li 2014). 
Although there are opposing views on whether intuition always serves as default or whether it runs in parallel and competes for primacy with reasoning (Evans 2008) the existence of two information processing systems, and their fluid interface, remains undisputed.

The intuitive mechanism is activated in fast-paced, ambiguous, or uncertain situations when we do not have access to adequate information or time to process it (Behling and Eckel 1991; Wally and Baum 1994; Parikh et al. 1994), which are frequent conditions in today's business environment. Under some circumstances this type of information processing serves us well. The coveted decision speed is attributed to its holistic, non-sequential processing of data that can be likened to a jigsaw puzzle built in a haphazard manner until the resultant, albeit incomplete picture becomes apparent (Sinclair and Ashkanasy 2005). This is possible because intuition works with (mostly non-verbal) associations (Epstein 1990), which accelerates the decision-making process. As such, it is inherently suited for non-conscious matching, approximation and/or re-integration of information, rather than highly accurate abstract processes involved for instance in mathematics. In high-pressured situations, we therefore sometimes circumvent time-consuming systematic evaluation and allow our brain to match or reorganize stored memory patterns in an expedient, non-linear way without our conscious intervention (Simon 1987). Such an approach has been frequently recorded in professions dealing with crises that require a fast decision (Langan-Fox and Vranic 2011). The result is often a non-conscious intuitive judgment (Dane and Pratt 2007), the accuracy of which is contingent on the level of domain-specific expertise (Baylor 2001; Kahneman and Klein 2009). This means that expert intuition is a reliable decision-making tool in such situations only for those with high levels of expertise. Recent research suggests this kind of intuiting draws on patterns stored in declarative memory (knowing that) while a different neural configuration may be in place in conjunction with procedural memory (knowing how) that maps "input stimuli or factual knowledge into actions or ideas" directly while our attention is directed elsewhere (Dreyfus 2014, p. 23). In view of its different purpose and functionality, Dreyfus calls it System 0.

In either case of processing, the advantage of expert intuition is that it can sift through huge amounts of data and deal efficiently with ambiguous situations that would otherwise stifle or protract deliberation. In less time-pressured contexts, when conscious deliberation has the tendency to interfere with intuitive processing, it can be diverted to another activity. For example, marketing research found that people made a superior choice of rental apartment when facing conflicting criteria if they were distracted by another task before making the final decision (Dijksterhuis 2004).

More recently, interest in the study of non-traditional decision-making has extended to entrepreneurial intuition (Crossan et al. 1999; Hodgkinson et al. 2008) and creative intuition (Dörfler and Ackermann 2012) that appear to have unique characteristics. Contrary to expert intuition, entrepreneurial decision-making tends to combine memory patterns in a novel and creative way that draws on a broader pool of memory fragments, often reaching beyond the discipline of expertise (Sinclair 2010). This accounts for a higher success rate of such intuitive decisions among novices (Baylor 2001) who may not have much 'technical' expertise but can connect data associatively with seemingly disparate information gleaned from everyday experiences (Sutcliffe et al. 2016). It also explains the, sometimes, protracted incubation period before the intuitive decision emerges into consciousness (Goldberg 1983), as often reported by inventors and scientists (Salk 1983; Monsay 1997). Naturally, this process contradicts the speed of expert intuiting (Sinclair 2010). Due to its high degree of novelty, it is plausible that the decision-making process is more strongly infused with affect/emotions (Bechara 2004). One would therefore expect a higher activation of memory patterns stored in the body as somatic markers (Damasio 1994) as more intuitive information is transmitted through emotional pathways. This is consistent with Dane and Pratt's understanding of intuition as 'affectively charged judgments' (Dane and Pratt 2007, p. 1008). As a result, entrepreneurial intuition does not necessarily offer the benefit of speed but provides a venue for decisions 'out of the box' incorporating aspects that would otherwise go unnoticed. Creative intuition appears to have similar characteristics but emerging theory suggests that its key difference from expert intuition may not lie necessarily in the engagement 
of different neural networks but rather in its focus on problem-solving (instead of decision-making) that entails a unique dynamic. That is why Dörfler and Ackermann (2012) put forward a case for distinguishing between "intuitive judgment [where] the decision aspects are tacitly integrated into a picture about what to do ... [and] intuitive insight [where] the components of the domain knowledge are tacitly integrated in a novel way producing knowledge that did not exist before." We argue that in the VUCA environment of constant flux, decision-making models need to be expanded to include problem-solving mechanisms. The intersection of decision-making and problem-solving is especially poignant in organizational improvisation, as discussed later, where intuition may provide the connecting link (see Batista and Cunha (2008)).

We know less about group intuitions (and how they inform decisions) that arise from collective consciousness (Sinclair and Hamilton 2014). Emerging research into intuitive group problem-solving suggests that individuals, if they are primed to set the same intention, can intuitively uncover various aspects of the same problem that can be then consciously integrated into a much richer and clearer solution that is not contaminated by personal or organizational biases (Sinclair and Hamilton 2014).

Both individual and group intuition may be better understood through innovative research methods such as those developed by Petitmengin (2006, p. 189) to "help a person become aware of the usually unnoticed part of a given cognitive process, and to describe it with precision." Through her elicitation process it has been possible to ask study participants to recollect intuitions in advance of epileptic fits. Such early and precise identification is a very personal early warning system that can be used by these individuals. This specificity and quality of forecasting was previously believed impossible because it was considered impossible for individuals to generate such minute awareness (Petitmengin 2006). The Petitmengin elicitation process can also be applied skilfully within groups-a point the methodology of this paper uses, to a limited degree.

Intuition research thus offers a complementary perspective to reasoned decision-making and paves the way to an integrated decision-making model that reflects more accurately the variation in awareness that we hold when we process information in today's dynamic world. It gives more credence to decisions we cannot fully justify rationally and teaches us to pay more attention to intuitions as a source of information that might otherwise go unnoticed (Dane 2011). Because of the intangible nature of intuition, it is necessary to create a supportive environment (internally through introspection facilitated by mindfulness and externally through increased confidence in intuitive skills aided by supportive organizational space) that will allow us to access this resource more easily, both internally and externally. On the research front, it forces the development of new methods to study the phenomenon, which can inform other disciplines as well. It has obvious benefits for practice, as it builds a foundation for the development of practical decision-making tools. As Dane and Pratt (2007, p. 49) suggest, "research on intuition is inherently practical".

\subsection{Wisdom}

In attempting to reconcile Eastern and Western perspectives, Li describes wisdom, (Li 2012, 2014) as higher-order insights available into complex, dynamic and uncertain issues. Based on the ancient Chinese concept of "Wu", he expands the Western understanding of wisdom as the evaluation of insight and adds a whole new (Eastern) layer that focuses on the creation of insight. In other words, the former cognitive process deals with exploitation of ideas while the latter is focused on their exploration. This naturally requires different information processing at different levels of consciousness and helps explain findings from entrepreneurship research. Entrepreneurs typically seem to use intuition in the edging and retreating phase of sense making (Teerikangas and Välikangas 2014). Incorporating both processes opens the possibility of a different way of knowing and offers another useful tool for contemporary decision-making. Particularly, it suggests a fluid model for integrating different modes of information processing, as suited to the activity and context of each fleeting moment.

To understand the unique value of the expanded view of wisdom, it is necessary to more fully understand "Wu". Specifically, "Wu" refers to intuitive imagination aimed at generating insight 
via metaphor, using mindfulness to enhance receptivity to conflicting information. Within Western scientific disciplines, there are also investigations of practical wisdom (Shotter and Tsoukas 2014). There are both similarities and differences between the two conceptualizations. In common between the two is the integration of past, present and future; and the integration of thoughts, feelings, and somatics. Whereas "Wu" is imaginative, "phronesis" (practical wisdom) draws one's attention to a moral framing (Shotter and Tsoukas 2014, p. 234), which, so far as we can discern, is missing from the Eastern teaching. "Wu" focuses instead on "proactive insight-making" (p. 38), which necessitates the inclusion of conflicting views. As the core process of creative cognition, "Wu"-based intuition therefore encompasses both conscious and non-conscious processes and is much broader, and more conciliatory, than the Western notion of wisdom. To make a clear distinction from the non-conscious System 1 and System 0, and the conscious System 2 (Evans 2008; Kahneman 2011), Li calls it System 3 (Li 2012) and sees all four systems nested in layers like an onion.

The usefulness of "Wu" lies also in its permeability allowing for the integration of contradictions, without the need to reconcile or reduce them. In this way, it helps expand the Western understanding of decision-making and challenges choices that might be false dichotomies stemming from a more limited view (Li 2014; Teerikangas and Välikangas 2014). On a systems level, this opens up the possibility of integrating conscious and non-conscious information processing in both System 1/0 and System 2, as it pertains to their respective exploitative and explorative functions. This offers an explanation for parallel and competing (vs. default interventionist) dual-process theories (Evans 2008) that posit an equal position of both information processing systems, continuously competing for primacy, by proposing a fluid mechanism for their interaction.

In respect of (Western) decision-making, "Wu" is a largely untapped area of investigation. However, it is possible to conceive that its holistic nature allows for the combination and re-combination of both tacit and explicit knowledge. This may be achieved through an integration of intuitively and rationally processed information, which may be more accessible in a mindful state to generate more novel and previously unseen decisions. At this point, in view of the current research paucity, such reasoning remains an educated conjecture.

\subsection{Organizational Space}

Organizational space is derived from the theory of social space, elaborated by Henry Lefebvre (Lefebvre 1991). According to the French sociologist (Lefebvre 1991, pp. 11-12): "space is produced through bringing together the various modalities of space-physical, mental and social-into one logic-epistemological space, the space of social practice, the space occupied by sensory phenomena, including projects of the imagination". Specifically, organizational space (Yeung 2005b) may be considered as a form of "social space", embedded in the organizational system. The process of decision-making does not happen in organizational vacuum (Nonaka and Takeuchi 1991), it is embedded in the organizational context and related to social interaction. This relatedness occurs in the "space" of knowledge called "Ba" (Nonaka and Konno 1998; Von Krogh et al. 2012). "Ba" can be a physical, virtual, mental, or affective (emotional) space, characterized by the emergence of embedded and situated bodies of knowledge (Nonaka et al. 2006). Within such spaces, it is possible for decision makers to transcend the individual and to become engrossed in a social process of heedful interrelating (Weick and Roberts 1993).

Intuition, mindfulness, and wisdom have been studied so far mostly at an individual unit of analysis but this ignores our collective and, therefore, social side. Homo sapiens are social animals and therefore, human systems can be characterized by the emergence of specific group, and social behaviors (Baylor 2001; Wegner 1987). By way of example, "group minds" (DeDeo 2014) are "mental properties that differ from the individual minds out of which they are constructed." (Dreyfus 2014, p. 17). As such, the concept of collective mind is more than the sum of single parts (Sutcliffe et al. 2016). This collective view of decision-making is explored in concepts such as organizational space. 
Organizational space is produced by ongoing relations within and between organizations and its configuration is intrinsically dynamic. Since space, in the sense used herein, co-evolves together with the web of intra- and inter-organizational relationships, it is interpreted as a fluidly emerging phenomenon, typical of complex organizational systems (Maimone and Sinclair 2014). However, with e-mediated businesses, organizational space is not always about the physical. It is a kind of topological configuration emerging from social interactions (Yeung 2005a, p. 219). Therefore, space is a social-relational reality that goes beyond the material dimension of the architecture of physical spaces and the office lay-out (Kornberger and Clegg 2004). As such it is possible for one organization to produce several organizational spaces. The theory of organizational space is relevant to decision-making through the patterns that are enacted within an organization, across teams and formal business units. These patterns may operate at the individual level or favor collective decision-making.

Decision-making processes do not occur in a vacuum, but are enacted in a living work place, where different organizational spaces may be present. If we "reason with our body" (Oullier and Basso 2010, p. 293), i.e., process information intuitively, and our body is contained within a space that includes other individuals, we again see layer upon layer of interaction: architectural, individual, and social. Therefore, we may assume that decisions are "socio-spatially bounded" and awareness to these aspects and how they may fluctuate would contribute to our understanding of decision-making.

\section{Social Improvisation}

Continuing the theme of the social nature of organizations and decisions, improvisation embraces the interdependent nature of decision-making. Improvisation in organizational context is understood as "spontaneous, intuition-guided action" (Crossan and Sorrenti 1997). It has been identified as a "combination of intuition (Maimone and Sinclair 2014), creativity (Amabile and Khaire 2008), and bricolage that is driven by time pressures" (Leybourne and Sadler-Smith 2006). This process of interdependency is best illustrated through the metaphor of the "jazz band", proposed by Meyer and Weick (Meyer et al. 1998): once the performance begins each player is free to improvise, the members of a jazz band do not decide in advance what each is going to play. The point is to depart from the original composition but stay close enough that others can synchronize. In strategic decision-making, organizational decision makers, much akin to jazz musicians, are intuitively attuned and respond to each other's actions to create an organically emerging outcome within predetermined parameters. If they are skilled, their decision-making process becomes "innovative, surprising and adaptive" (Eisenhardt 1997, p. 2) without compromising quality or proper execution. It is possible that in an environment that supports mindfulness, intuitions are more acutely noticed and wisdom more likely to be generated through exploration and shared through interactions in organizational space.

Organizational improvisation is unlikely to occur in a vacuum. Moorman and Miner (Moorman and Miner 1998) affirmed that organizational memory is bi-directional: the past influences improvisation in decision-making and improvisation, on the other hand, has an impact on organizational memory. So, we may assume that improvisation in decision-making is also influenced by the dynamics enacted within and across organizational spaces. In a parallel line of theorizing, Morgeson and Hofmann (1999) pointed to a similar dynamic suggesting that social structure comes about through the agency of individuals but also limits this agency. Hence, the ability of individuals to improvise is likely to be constrained by the social space in which they find themselves. This has consequences for decision-making. The ability to extemporize could be shaped (limited or accentuated) by the space in which individuals function as well as the extent of their knowledge, which may fluctuate across spaces. Similar to Baylor (2001) U-shaped model of intuition that proposes a varied use among experts and novices, improvisation theory suggests that each group improvises differently for different reasons. While experts draw on their extensive expertise and experience (declarative and episodic memory) in the vein of expert intuition, novices reach out for intuition because they lack in this respect (Batista and Cunha 2008). To compensate for this deficiency, novices resort to 
improvisation or draw on schemata from other disciplines, thus encouraging thinking out of the box (which is reminiscent of entrepreneurial intuition). That is why, for example, hotel industry recruited experts in revenue management from such distant fields as railroad logistics or plane manufacturing (see Sinclair and Sinclair (2009)).

\subsection{Summary}

In the above review, we have chosen five different perspectives as prisms through which to look at decision-making under VUCA conditions. Although they overlap and relate to each other in multiple ways, each offers a unique contribution to handling the fluid, ambiguous and continuously changing environment of decisions made in today's business world while shedding light on the richness of awareness to aspects that are under-accounted for in rational perspectives.

In Figure 1 below, we depict the research framework that has emerged from our literature review, laying the five explored perspectives side by side and using them additively. As the figure illustrates, they contribute to decision-making states at both individual and social levels. This framework provides a visual map of the complex and multi-layered way that these perspectives relate to each other, and to the dynamic and frequently changing states that decision-makers in today's business world find themselves in. It informs our empirical investigation below, and outlines the relationships between perspectives derived from the literature.

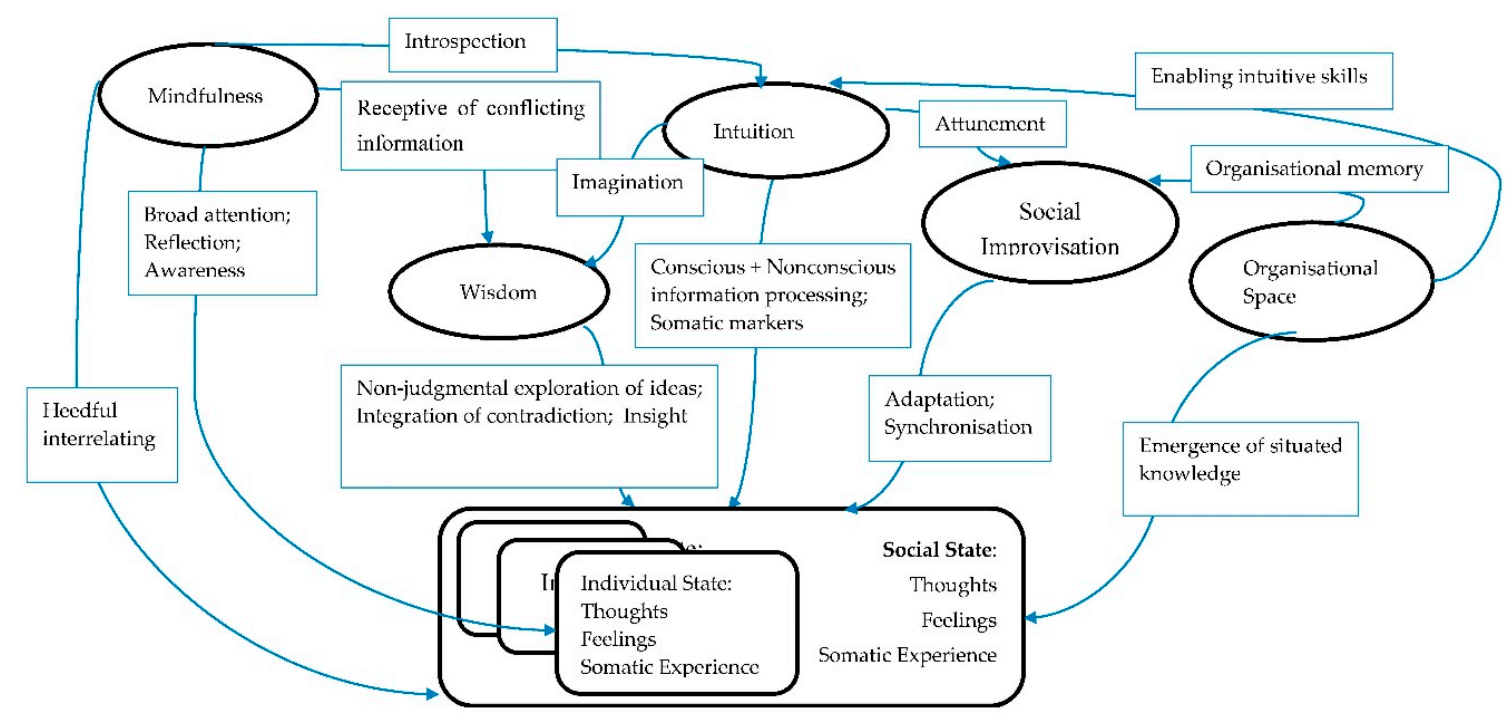

Figure 1. A framework for integrating five non-rational perspectives impacting decision-making states.

Through our theoretical explorations, we came to view mindfulness as central for all examined processes as it helps the individual and/or collective mind to introspect and switch to 'broadly focused attention', which are overall conditions for receptivity to intuition, wisdom, and social improvisation. Mindfulness 'primes' our access to intuition, among other things, through the activation of peripheral vision (Cappon 1993) and non-striving acceptance (Kabat-Zinn 2005) that, for Western mind, are often attributes absent from common business practices. That is where we found the Eastern view on wisdom, "Wu", to be useful: not only does it provide a mechanism for non-judgmental observation but also for non-discriminatory acceptance of conflicting views. And since none of these activities occurs in a vacuum, organizational space offers a physical, psychological, and social environment where introspection (needed for mindfulness, intuition, and wisdom) can flourish but also encourages group processes leading to group intuitions and organizational improvisation. This is an important mechanism for a fluid interaction between individual and social processes. As we concluded earlier, in mindful environments intuitions are more acutely noticed and wisdom can be generated through exploration and shared through interactions in organizational space encouraging further improvisation. 


\section{Methods}

At the Annual Meeting of the Academy of Management, 2016, the authors hosted a Professional Development Workshop (PDW) allowing them to engage with an academic community and discuss the five outlined perspectives on decision-making. The authors created a scholarly exchange reflecting the complexity and richness of the topic at hand. While showcasing the contributions of non-rational perspectives was the first intention, the second intention was to create new knowledge by adopting an iterative and innovative approach that facilitated both the integration of different theoretical perspectives and a decision-making experience designed to unearth new insights. The three-hour PDW involved 40 academics and practitioners aligned with the latest debates on decision science. In effect, the workshop became a crucible in which existing knowledge could be integrated and new knowledge created.

Participants registered to attend the PDW, which was entitled Innovative Approaches to Improving Organizational Decision Making: Theory, Method, and Practice. The agenda comprised four inter-related sections (see Figure 2 below). The first session of the workshop was a panel presentation by five leading scholars who provided an integrated theoretical overview. The presentations were followed by a short meditation to help induce mindfulness and to allow the ideas provided in the theoretical overview to "sediment" and to help participants move from a mental modality to a somatic modality in readiness for the next exercise. Participants were then invited to take part in an experiential exercise in table groups, in which each group was tasked with coming to a decision in the face of ambiguous information and within varied contexts. Finally, the experiences of the participants in the group work became the foundation for a plenary discussion and collaboration to build new knowledge. This discussion was a way of building new knowledge and incorporating individual and collective perspectives from the participants into the proposed theoretical framework we have outlined above.

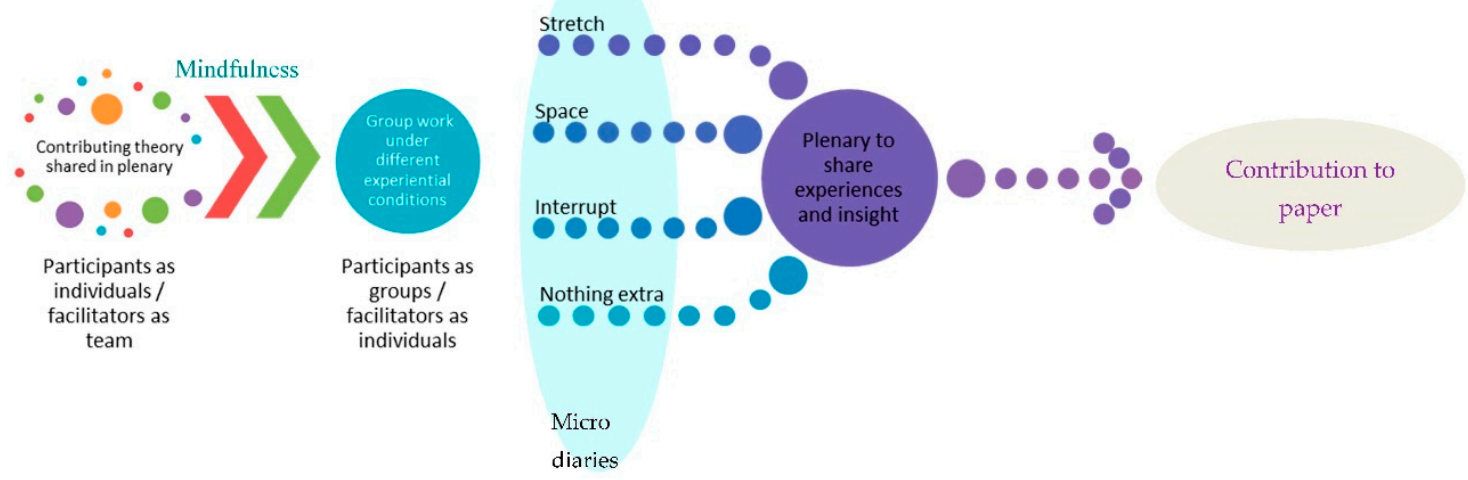

Figure 2. Schematic of Participant Experience at the AoM PDW.

The PDW became a laboratory for a small social experience of decision-making and it is this experience that provides the basis for our empirical findings.

Guided and mentored by the facilitator team, participants joined any of several possible table discussions, forming a work group. At each table, participants and facilitators faced varying forms of uncertainty and complexity with many people interacting in processes that were under-specified. This ambiguity left individuals, and the table groups in which they worked, to undertake their own sense making of the situation before collectively deciding. Tables were divided into four different experiences: one was allocated to promote a mindfulness experience; one was allocated to encourage a social space experience; one to an intuition-conducive experience; and one to work "as normal".

Each group was provided with an identical picture riddle to solve (see Appendix A for several examples), as a proxy for sense making and decision-making, but each group experienced their own unique mid-task break designed to interrupt (or maintain) the decision-making process, as previously 
determined by the facilitator team, based on available literature. The mindfulness group was invited to participate in a physical stretch (Langer and Moldoveanu 2000); the social space group walked around the room and then continued their discussions while standing (Nonaka et al. 2006); the intuition group was invited to play another mind game (by way of distraction; see Dijksterhuis (2004)); the fourth group was left to simply work uninterruptedly on the picture puzzle. Subsequently, all participants and facilitators discussed how individuals and groups had made sense of the picture riddles, and how the quality of decision-making was impacted by different factors within and between individuals and across groups. Permission was obtained from participants and facilitators to use their personal records in this paper. A schematic of the PDW (Figure 2) is provided below.

Rather than measuring decision outcomes, the focus of this experience was to gain novel insights into some of the antecedents and outcomes of social decision processes. To gain in-the-moment understanding of participants' ongoing experiences, each participant recorded their thoughts, feelings, and bodily sensations in a micro diary, and similarly, the facilitators who led the workshop provided post hoc their own micro diaries to illustrate their momentary experiences (see Supplementary Materials for further details). Micro diaries where chosen as the primary approach to data collection, because they allow for very small interruptions whilst participants are engaged in a fluid process. The diaries were expected to provide multiple time-sliced responses like that achieved in Experience Sampling Method (ESM) (Fisher and To 2012). Both Gendlin and Petitmengin (Gendlin 1995; Petitmengin 2006), for example, have demonstrated that it is possible to reconstitute sensations whilst narrating the experience of sensations. Although in both cases this is usually achieved verbally, we hoped that micro diaries would help participants bring to consciousness that which is usually "below the threshold of consciousness" (Petitmengin 2006, p. 230).

Our choice of micro diaries was also influenced by the growing trends associated with social media, where individuals are inclined to engage in multiple but fragmented conversations simultaneously (Faulkner and Culwin 2005; Deloitte 2016).

Although the participants' micro diaries provide an individual unit of analysis of the experience, they also give insight into the group unit of analysis. In keeping with the principles of "Wu", we have taken the liberty of mixing together units of analysis: individual and social; together with levels of analysis: micro, meso and meta. This matrix approach allows us to jump from the very small individual sense making to the much bigger group intuiting. Leaps of this type provide insights and novel understandings that when presented statically, do not accurately represent the dynamism of the phenomenon. The following section presents the findings and extracted narratives from the micro diaries. Irrespective of source or structure, each diary provides a window into the unique universe of the individual taking part in this workshop.

\section{Results}

Thirteen participant micro diaries were handed to the authors. The template requested participants to record: thinking, feeling and bodily sensations in tabular form, but not all participants completed all fields. Under "thinking", all participants completed all the fields; under "feeling", all participants completed some fields; under "bodily sensations", 11 of the 13 participants completed some of the fields. This suggests that to some participants "bodily sensations" as a description did not make sense or, they were unable or unwilling to get in touch with somatic experiences and record them.

This section provides extracts from participants' micro diaries. They offer a rare insight into the internal workings within individuals in the three domains described as they encounter a knowledge sharing event and face a decision-making task with strangers. Through these micro diaries we explore the domain of thought, affect and bodily sensations. These excerpts demonstrate how non-rational elements can subtly influence the decision-making process and moreover, how dynamic the impact of these elements can be.

"Wu" suggests that these multiple perspectives can be jointly held without rushing to reconcile contradictions and divergences. Following this open and explorative vein, the internal, interpersonal, 
and collective narratives, the participants' and facilitators' feelings and somatic states are explored in the findings below.

\subsection{The Experience of Participants}

\subsubsection{Individual Differences in Decision Experience}

Participant 10 shows, in this time-sliced account how internal states vary from moment to moment. The diary illustrates how state might affect the decision. For example, the urge for coffee may make things hurried and unconsidered. A small piece of happenstance-meeting a fellow national-changes the mood dramatically. Over the course of approximately $20 \mathrm{~min}$ this micro diary is a demonstration of the flux and flow of mind and body:

In common with Participant 10 (Table 1), the next participant records a change of mood following an interval of stretching. This micro diary highlights how the somatic experiences of the body show up in both thoughts and feelings.

Table 1. Participant 10's micro diary.

\begin{tabular}{|c|c|c|c|}
\hline & Thinking & Feeling & Bodily Sensations \\
\hline $09: 45$ & $\begin{array}{l}\text { making sense of these } \\
\text { pictures collectively }\end{array}$ & $\begin{array}{l}\text { I do not see the point of } \\
\text { the exercise; can we skip } \\
\text { to the "conclusion"? }\end{array}$ & $\begin{array}{l}\text { all the good work of the mindfulness } \\
\text { practice session lost-feeling anxious! } \\
\text { Time for coffee! }\end{array}$ \\
\hline 09:49 & $\begin{array}{l}\text { found a common } \\
\text { nationality in the group }\end{array}$ & happy & someone suggests stretching \\
\hline 09:55 & $\begin{array}{l}\text { We're coming to } \\
\text { conclusions-deciding } \\
\text { relieved to hear others }\end{array}$ & $\begin{array}{l}\text { much more relaxed } \\
\text { about the exercise } \\
\text { curious about how this }\end{array}$ & $\begin{array}{l}\text { now great, feeling less tense in me } \\
\text { back/arms relaxed }\end{array}$ \\
\hline 10:07 & $\begin{array}{l}\text { felt tense/anxious about } \\
\text { the decision exercise too }\end{array}$ & $\begin{array}{l}\text { happens; why were we } \\
\text { tense about pictures }\end{array}$ & time for caffeine \\
\hline
\end{tabular}

Over a similar time-period, state-volatility is also demonstrated by Participant 4 (Table 2) but whilst the range is similar the content is different.

Table 2. Participant 4's micro diary.

\begin{tabular}{cccc}
\hline & Thinking & Feeling & Bodily Sensations \\
\hline 09:42 & why are these surprising & $\begin{array}{c}\text { a bit confused } \\
\text { a bit embarrassed at the } \\
\text { "double }[\mathrm{xxx}]^{\prime} \text { picture }\end{array}$ & nervous, anxious \\
09:50 & this was fun & more mixed & not as sleepy \\
09:52 & $\begin{array}{c}\text { approach to deciding, } \\
\text { I should do this more often }\end{array}$ & m & \\
\hline
\end{tabular}

Participant 5 (Table 3) makes a special mention of the effect of stretching on their state, but does not expand this comment further under "bodily sensations".

Table 3. Participant 5's micro diary.

\begin{tabular}{ccc}
\hline & Thinking & Feeling \\
\hline Time not provided & $\begin{array}{c}\text { how relaxed I am } \\
\text { I am a little frustrated not knowing what pictures are } \\
\text { stretching helps return balance }\end{array}$ & $\begin{array}{c}\text { happy-open to learning } \\
\text { need to figure this out } \\
\text { feeling better to look at pictures }\end{array}$ \\
\hline
\end{tabular}

Participant 7 (Table 4) shows how transient feelings can be. The "early" and "later" are undefined, but the group work only lasted $20 \mathrm{~min}$ - so this turnaround occurred within that timeframe: 
Table 4. Participant 7's micro diary.

\begin{tabular}{lcc}
\hline & Thinking & Feeling \\
\hline Early & Imagination & Relaxed \\
Later & trying to think out of box & Frustrated \\
\hline
\end{tabular}

The next two micro diaries are the only two in the collected data that are cross-sectional and therefore no change is recorded.

Participant 2 simply records their positivity: "this is fun, bouncing ideas off each other, joyous, playful, accepting, feel awake".

This is in stark contrast to Participant 9, who recorded: "what a challenge, Stuck".

As outlined in the previous section, there is interplay between the individual and social levels of decision-making. In the following micro diary (Participant 11, Table 5) this interplay is demonstrated quite starkly; the process that a group goes through seems to have an important impact on individual affect. They note that the group is stuck on the comments of one or two contributors, resulting in this individual's frustration. This emotive charge could potentially get in the way of constructive conversations. Below we see that the process has activated difficult thoughts and feelings for one individual, which will likely have an impact on the social level.

Table 5. Participant 11's micro diary.

\begin{tabular}{|c|c|c|}
\hline Thinking & Feeling & Bodily Sensations \\
\hline $\begin{array}{l}\text { why only two sheets with pictures for } 6 \text { people } \\
\text { why [are] we taking the first suggestion }\end{array}$ & $\begin{array}{l}\text { frustrated, extroverted } \\
\text { bored, no creativity }\end{array}$ & Headache \\
\hline still anchoring & frustrated, [discussion] hung on one or two people & Tired \\
\hline
\end{tabular}

The foregoing micro diary study demonstrates how participants' internal state contributes to their ability to concentrate. Also, their internal state changes what they might say and how they might say it. All of this can have a material effect on the nature of the discussion and the subsequent decision.

\subsubsection{Changing Experiences over Time}

Further, the micro diaries demonstrate that affect states fluctuate wildly and frequently. Small things matter: a stretch, a new voice, a joke. Almost anything can change the tenor of the conversation. People's states are mostly volatile. Only three of the diaries recorded a singular state throughout the group exercise; all the others illustrate mood fluctuations and how this affected thinking and willingness to engage.

In this low-stakes environment, these fluctuations were of little consequence to the group outcome. However, in high-stakes situations it is possible that people remain on autopilot and are largely unaware of how their state is influencing their decisions. Within the different experiences in the workshop, we do not have sufficient data to say which intervention (stretch, walk, distract or without interruption) had the biggest effect or the best effect. Based on the small amount of data collected, we can suggest that the different interventions did have an effect and sometimes, a detrimental one. For example, the distraction exercise that occurred whilst one group was in full flow was reported in the diaries as disruptive and intrusive.

\subsection{The Experience of the Facilitators}

This section examines the four facilitators' micro diaries containing their post hoc reflections of the workshop. Their diaries did not follow the same structure as participants' (thoughts, feelings, and bodily sensations), and were largely structured in a linear fashion tracking their experiences over time. The excerpts in the section below demonstrate how intentional and unintentional factors can shape the social space within which decisions take place. Moreover, the extent to which an individual 
is aware of their own thoughts and feelings begins to reveal how behavior follows and, thereafter, how individuals interact with others to create a social space.

\subsubsection{Individual Differences in Decision Experience}

The following excerpts illustrate a high level of self- and other-awareness and self-monitoring, which makes the facilitators' behavior distinct from that of participants. The recalled incident suggests that each facilitator flexed their behavior to subtle changes in the environment, and that their decisions were affected by other people's actions.

F2 “I came early, still jet lagged and felt immediately relieved that all co-organizers were there already and clearly focused on the task at hand; I felt that I did not have enough time to spend with [name] as we were meeting for the first time and it would have been helpful to have a few minutes to make a personal connection before the PDW started ...

Just as I got oriented and was about to give co-organizers a hand, the other two speakers started arriving. Since I was the only one who knew them in person, I quickly re-focused my attention on them to make them feel welcome, comfortable and introduce them to each other and the organizers...

I was relieved to see that in the meantime my co-organizers 'worked the room' and greeted all incoming participants, which broke the ice and created an atmosphere of inclusion. It was also encouraging to see that the room filled up despite the Friday morning slot."

F3 "I am aware of my own narrative about my limited contributions to the PDW so far and how this impacts my willingness to engage with others as a "host"."

F4 "I consciously took some actions to help build a psychological container for the participants. For example, I went around and shook hands and personally introduced myself, stopping occasionally to have a light-hearted word with a few people. I encouraged people as they entered the room to move to the front tables not simply stay at the tables at the back. I deliberately used words to indicate inclusion: sit anywhere, we're very informal..."

\subsubsection{Changing Experiences over Time}

In this next selection of facilitator excerpts, we see a direct parallel with the internal experience and the outer experience. In many of the same ways as the participant diaries, these excerpts show a pattern of fluctuating and divergent individual states as reflected in thoughts, feelings and bodily sensations. Each facilitator brings to the workshop their individual state, which in turn is affected and moderated by her experience of the interpersonal state, located (and constantly shifting) in the space between her and the co-facilitators as the workshop unfolds.

F1 "[during the break] We wandered around a bit, but I was nervous that few people would come back. The conversations outside the room were very engaged though, so I thought, just go with it. “

F2 "Surprisingly to us, most participants returned after the break even though they were very cold and most of them could not locate coffee ..."

Many people wanted to talk to me during the break, even in the restroom; definitely there was interest generated. One participant even invited a few of her colleagues to join us after the break, they asked me for permission." 
F1 "Loved that [final] session, loved the flow of it, and although I was struggling somewhat to put onto slides what people said, the atmosphere in the room felt great. As time moved on and got close to the top of the hour, I spoke up and reminded people that we needed to stop to get everyone to their next session on time, and while I didn't like doing that (the atmosphere in the room was so constructive and friendly), I thought it was the right thing to do, and everyone did get out on time. The conversations at the end were full of energy, and I felt immensely grateful to my team for having created something really beautiful."

F2 "It was good to give people space to talk and share, I was grateful that [name] typed their comments, not only for us but also for them to see. I knew that we were running out of time but still interrupted and asked participants what we should add to our model. I felt it was too important to leave it out."

Although retrospective, these diary entries again illustrate how an individual's internal life and self-talk shines through in the choices they make and how these internal experiences manifest in behavior and interpersonal interaction that can then influence the social setting and further decisions concerning how to interact and/or what to focus on.

\subsubsection{The Emergence of Divergent Interpretations and Counter-Interpretations}

The reflective diary excerpts below demonstrate that each facilitator is watching the room and making individual choices in response to their observations of the social dynamic emerging. They show that any single event can trigger multiple interpretations and that from individual experiences, group intuition begins to form. Here, there is a subtle incident at the start of the panel discussion where F2 has chosen to stand and F1 has chosen to remain seated. Both facilitators remark on their internal dialogue and both have intuitively understood each other's differing intentions and decided not to rescind previous decisions to stand or sit.

F1 "[name] stood up for the first time, I was a bit concerned that this meant lots of big speeches, and I decided not to stand up myself. When [name] and [name] stood up as well I doubted my decision somewhat but because I felt I had to look at my notes from before, and from taking down notes whilst the other speakers spoke, I decided to stick to that decision. It seemed right."

F2 “I cannot comment on the content of answers to each question as I was focused more on the organizational side of the discussion (how we organized ourselves and how the audience responded-I watched their facial expressions.). Since my seat was partially obstructed by the lectern, I stood up so everybody could see me. Naturally, [name] and [name] followed suit. I noticed that [name] remained seated and figured that she wanted to make the atmosphere more casual and inclusive through the gesture."

Later, in the panel discussion another group-intuition arose, this time involving F1,2,3 and 4. One of the speakers was overly zealous in their contribution to the panel and was hence encroaching on the speaking time of others. The internal sense making of each facilitator demonstrates equal measures of concern for the speaker and the integrity of the workshop. It may also suggest that the alignment of group intuitions was increased due to the shared intention to facilitate an all-inclusive and integrative workshop and allow for the unexpected. In this way, the cohesiveness of the facilitators suggests that they were, as a result, in 'psychophysiological coherence' (Bradley 2011).

F3 “... [name] runs on long without awareness of his time and other's efforts to cue him; panel gets noticeably uncomfortable; I feel anxious for him; [name] is noticeably concerned"

F4 "I need to interrupt [name]. So, I stand and wait. He's not seeing me or not wanting to see me. I take a step forward. No acknowledgement. Inside my head is now busy 
making judgments on how best to interrupt. Worry about the power of doing so. Am I ego-motivated; am I preventing the participants [from] hearing more. Without action, I am robbing the others in the panel of time. I speak."

F3 "Similar experience occurs where there are strong responses from the panel to the facilitator prompts and the audience is captivated; again, [name] needs to be managed."

F2 "As organizers, [name] and I were quite disciplined in our time limit, even though I think I went over in the last question. [Name] was very well disciplined and did not need much reminding. [Name], on the other hand, was so focused on his English speech and the desire to make a good impression in a completely new (to him) conference, that he not only did not see [name's] signals but did not even notice my gentle pulling of his sleeve.

F4 "I need to intervene again and use my standing and body language as a signal. [Name] and others have intuitively understood my physical signals. [Name] hasn't. I have to interrupt again. Worry, worry, worry about whether it is right to interrupt."

\subsection{Summary}

The diary excerpts depict decision-making as a flow process embedded within other flow processes akin to the process ontologies of Crevani et al. (2010) and Hernes (2007): where the individual and the collective give rise to and experience volatility, uncertainty, complexity, and ambiguity bringing about a cascade of inter-linked actions and reactions. This collection of participant and facilitator excerpts illustrate that events in the room had multiple interpretations and thence multiple responses. Facilitators particularly were constantly monitoring the situation, undertaking individual sense making and taking action accordingly. However, as the facilitators were also a team, guided by the shared intention (to facilitate an all-inclusive and integrative workshop and allow for the unexpected), each one was scanning the others and adjusting their behavior too. All of this had a constant ripple effect on the others. In some small way, this was a form of social improvisation by the facilitators, consistent with social flow theories (Crevani et al. 2010). It is interesting to note that despite understanding some of the precepts of unknowing (drawn from " $\mathrm{Wu}$ "), none of the facilitators could abide in that unknowing space. In fact, each facilitator took steps to reduce uncertainty through their actions. Given the multiple interpretations of a situation, each facilitator could take action based only on what they believed to be true and valid. In a workplace context, such an example might equate to enabling or disabling social improvisation within the organizational space. These overlapping cycles of interpretation and action and reaction have the potential to reinforce or dampen cognition, affect, and physicality within individuals and between/among them inside the room.

\section{Discussion}

In contrast to other interpretations of "integration" we have laid five perspectives side-by-side, integrated these in our research framework, and found ways to use each perspective in our analysis of the findings. We stress once again that unlike other attempts at integration, here it is taken to mean a way of expanding and including different academic studies. We have not simply collapsed the literature. In taking this approach, we have deliberately stretched our thinking beyond the usual Western paradigm of duality. On this premise, we present below four propositions as our contribution to theory and four propositions intended to contribute to practice. In addition, we provide two contributions to method.

\subsection{Theory Contributions}

Whereas it is generally recognized that today's social and environmental context for decision-making in organizations is marked by Volatility, Uncertainty, Complexity, and Ambiguity (VUCA), our empirical work suggests that VUCA should be considered as a more dynamic and 
human aspect of decision-making. Specifically, we propose that VUCA exists within individuals (internal), between individuals (interpersonal), and around the interpersonal space, throughout groups (collective). Our contention is that beyond the usual conceptualization of VUCA as a purely amorphous contextual issue, VUCA can be considered an internal, interpersonal and collective phenomenon.

Consistent with mindfulness, we find that individuals' experiences of phenomenon arise and fade (Kabat-Zinn 2013); affective states are impermanent. Further, through the content analysis of the narratives generated in the decision experience in the workshop, we demonstrate that individuals' somatic experiences reflect, amplify, and impact their thoughts and feelings and vice versa. This three-part exchange of thoughts, feelings and bodily sensations generates a multidimensional "state" that holistically affects decisions. This state is in a constant flux. As with the interactions of medical practitioners in the critical decisions vortex (Coget and Keller 2010) where analytical and intuitive processing fluidly interact; this small workshop shows a more nuanced and dynamic flux occurs within, between and among individuals, and appears to be more immediate. So, whilst decision-making is a single time point, it is possible that a different multiplicity of states at different time points would result in materially different decisions at another single time-point. In this light, decisions become an outcome of happenstance; an almost unrepeatable event along a timeline of change.

Hence, thought, affect and bodily sensations both create and continuously amend the internal, interpersonal, and social VUCA states-all of which impact decisions in an iterative and integrative way. This is demonstrated by the multiplicity, and multi-laterality of the narratives, of the different groups of decision makers in our empirical investigation. These conclusions resonate with those from research into organizational space where social interactions are likened to a dance that continuously (re)shapes responses by individuals as they contribute to group intuitions (Maimone and Sinclair 2014).

Based on this analysis, we have created a visual model of "VUCA in action" (see Figure 3 below), in other words, an illustration of the dynamic and fluid relationship between individual, interpersonal and collective decision-making states. All three of these levels of decision-making states impact each other in an iterative way, which in turn shapes the decisions taken by individuals and groups.

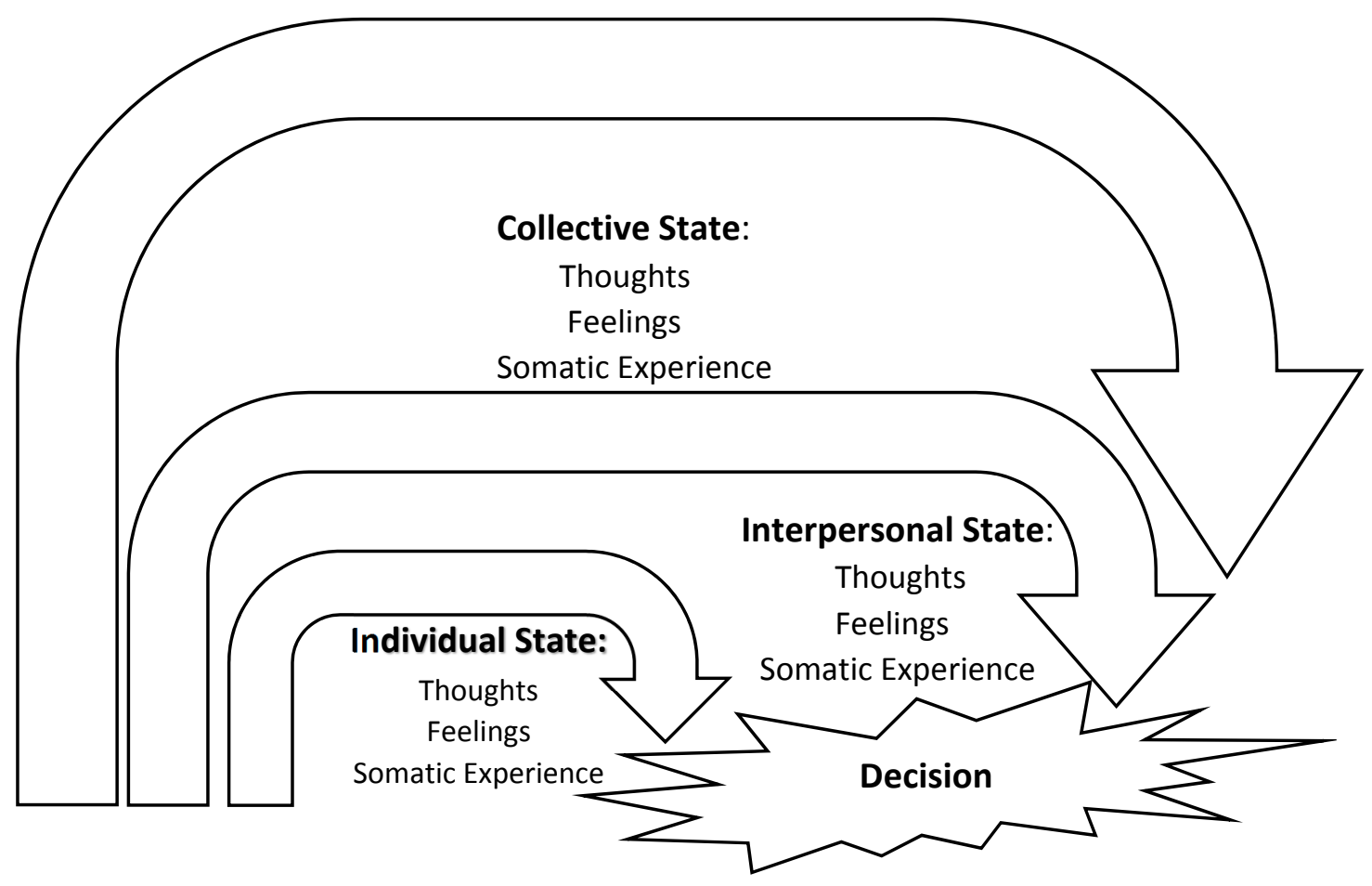

Figure 3. VUCA in action: A dynamic model illustrating how individual, interpersonal, and collective decision-making states are integrated and iteratively impact decisions. 
We therefore propose the following and invite further debate, regarding:

Theory Proposition One. VUCA, previously solely a contextual concern for organizations, is also an experience of the ever-changing human condition during decision-making.

Theory Proposition Two. VUCA exists inside an individual; in the space between individuals; and it marks the collective space within which a decision is shaped.

Theory Proposition Three. VUCA-intra, inter and social-is dynamic and its cumulative effects on decision-making are in constant flux.

These propositions represent a foray into new dimensions of relationships between individual, interpersonal, and social factors impacting decision processes and outcomes. Exploring each proposition in turn will help generate a new theory on the antecedents and outcomes of decision-making. Additionally, these propositions extend the reach and scope of VUCA by suggesting it impacts decision theory in a manner that is relevant to the present day. Accordingly, the micro diaries reveal the different levels of awareness of VUCA by participants and facilitators.

The requirement to fill in a micro diary is likely to have encouraged participants to become more aware of their experience as it occurs, uncovering and revealing to them their hidden thoughts, feelings and bodily sensations. Without the prompt to complete a micro diary entry, it is not clear how aware individuals would have been of their internal experience. Nevertheless, even with prompted awareness (Gendlin 1995; Petitmengin 2006), the diaries demonstrate that levels of individual awareness are highly variable and this notion aligns with progressive/developmental theories of mindfulness (Rinpoche 2003). It is therefore our proposition that contributors might be aware of awareness itself (meta-cognition) or they might not. By way of example from the micro diaries: one participant is craving coffee and might have used this awareness to suggest to the group that his concentration was lapsing and a break would be helpful. For another individual, an interruption was experienced as disorienting - and they might have pointed out that the group was in flow and it would be helpful to keep working without interruption.

A mindful awareness of state is a separate consideration to that of awareness of flux and flow, which is also variable (Begley and Davidson 2012). The complex psycho-physiological loop between cognition, emotion, and sensations can be brought to awareness with practice, but in the micro diaries there is no evidence that individuals responded to the self-revelations of state. The participants' diaries record that affective states surged and changed with their own momentum. Seemingly, no one took proactive steps to change their affective state. Where state-change was recognized and diarized it can be attributed to either natural happenstance or to planned interventions initiated by the facilitators. At the very least, it could be also that the intensity of the state, was affected by subtle external factors (embedded in the group space), such as the choice of words or the tone of voice, as suggested by research into effects of unconscious stimuli (Shevrin et al. 2012).

In summary, individuals vary considerably in their awareness of affective and somatic (physical) state, and this awareness also fluctuates over time. Those who are (or become) aware show some ability to influence their affective state. In the retrospective micro diaries of the facilitators, there is more evidence of social awareness and of instances where this type of awareness led to positive actions when it became consciously discernible to a facilitator. For example, decisions to stand or sit and whether or not to intervene influenced interactions between facilitators and, relatedly, their affective experience. Supporting this observation is research by Coget and colleagues (Coget and Keller 2010), who found that effects of the same discrete emotion on the choice of intuitive vs. rational information processing differed according to the previous emotional experiences of the decision maker.

Similarly, sensations that are just below the surface of awareness offer useful data. When we bring somatic experience to affect, and especially combine these into conscious awareness, then this provides new insights and aids the process of decision-making. We therefore propose the following: 
Theory Proposition Four. Individuals may be consciously aware of the effect of somatic and affective states and if so, may use this awareness as a further resource when deciding.

As suggested by Eisenhardt and Zbaracki (Eisenhardt and Zbaracki 1992), the four propositions above extend the strategic narrative in which the decision-making discourse is situated and suggest that further research will be enhanced by a wider investigative lens to consider more factors when studying this important domain.

\subsection{Practice Contributions}

As researchers, we have attempted to uncover and reveal more about the complex and dynamic nature of sense making and decision-making in a relatively small experiential workshop with colleagues. Despite the restricted number of participants, the workshop was not atypical of interactions throughout the workplace. In accepting this parallel, we suggest that practitioners need to take account of the multiplicity and complexity of fluctuating states of thoughts, emotions, and sensations at the three levels of analysis presented above. In the section below, we describe how the theoretical insights can influence practice.

The micro diaries show that individuals arrive to a situation "fully loaded", they are not empty vessels (Raelin 2007). People carry over thoughts, feelings and sensations derived from the previous events of their lives, whether that is the last few moments, few hours, or years. This has consequences in the workplace as people arrive to meetings or even to emails where they are being asked to take in new information or create new knowledge. Leaders of meetings and conveners of groups can help by ensuring that people have time and space to prepare internally for what is to come, possibly using the 'third space' technique, designed to help professionals bracket their private life from their professional 'emotional baggage' (Fraser 2012). The proposition below is intended to raise practitioners' awareness of this phenomenon.

Practice Proposition One. Internal, interpersonal, and collective somatic, and affective states are carried by individuals from one context to the next, and decision-making is impacted by these cumulative effects.

Similarly, construction of the physical space needs attention because physical configurations matter too. Our Western Cartesian mentality shows through in meeting rooms where we sit opposite each other. For example, the U.K. Parliament is two sword widths apart and sets up an oppositional House of Commons. Physicality sets the tone for "either/or" discussions, it reinforces that in choosing this we reject that. Conveners of decisions might give more consideration to the physical space. Our contention is that physical space (that in turn affects social space) can be made more conducive to " $\mathrm{Wu}^{\mathrm{u}}$, where there is no need to reconcile opposites and collaboration is encouraged through designed configurations.

In addition, small actions and events have the potential to subtly change a dynamic; to make it feel more pressured or more spacious. A friendly face, information not shared, a dark room or the absence of fresh air are not to be overlooked when analyzing decision outcomes (Tombs and McColl-Kennedy 2010). Marketing research has found that environmental factors or atmospheric effects can influence consumer behavior (Turley and Milliman 2000), as can social aspects such as the interplay between customers and service providers (Tombs and McColl-Kennedy 2003). Space and timing and some way of "emptying" may have the effect of slightly slowing the pace of decision-making but may have the commensurate effect on improving decisions. During the PDW we gave participants the opportunity to stretch, to walk around, to engage in other mental distractions. These were not universally successful一the distraction, for example, was disruptive for some participants. Nevertheless, stretching and walking did manifestly change the dynamic, frequently for the better. This is perhaps not surprising given research that has found that how an individual moves their body is related to their affective state and energy level (Peper and Lin 2012). Other practices might be more appropriate in a workplace setting: pausing 
and stopping occasionally for physical comfort breaks may have profound effects. In practical terms, the construction of the social space needs attention. In the context of decision-making, this attention to even small details seems to be beneficial, which leads to our second proposition for practice:

Practice Proposition Two. In a VUCA environment, small changes in any aspect of organizational space may have a big effect on somatic and affective states, and in turn on the decision outcome.

Individuals will have different predispositions, previous experiences, and worldviews that guide their interpretation of their ever fluctuating internal and external state, in a VUCA world particularly. Others too have a role to play in this interpretation. Building on the proposition above, our third contribution to practice is to call attention to the framing effect that facilitators can have on a discussion. Facilitators and/or skilful contributors can help participants to see how they are coping with feelings of discomfort, whether these arise because of VUCA conditions, and how these feelings might distort judgment in some way. At the very least, those who are most unsettled by VUCA are unlikely to contribute intuitive leaps of insight because of their preoccupation with their own discomfort. Skilful facilitation can normalize disquiet. The proposition below is therefore focused on the role of decision facilitators.

Practice Proposition Three. Facilitators of decisions can unearth diverse experiences of VUCA in the interest of helping individuals become aware of the effect of specific or cumulative states.

Finally, and importantly for managerial decision-making, mindfulness may have a significant role to play in moderating the course of decision processes. Mindfulness can be trained (Kabat-Zinn 2005; Brown and Ryan 2003; Langer 1992). The innovation here—or perhaps the paradox-is that practicing or applying mindfulness to work situations enables individuals and teams to generate more 'rational' decisions by processing information in ways that embrace mind-body experiences that stretch far beyond 'the rational'. For example, increasing one's awareness of bodily sensations whenever we make decisions seems to enrich the repertoire of choice available, as found in the present decision experience (Connelly and Gooty 2015). Mindful awareness may also facilitate access to intuition and wisdom (Germer and Siegel 2012). Past studies have found a link between the ability to listen to one's inner most voice and intuitive decision-making (Moorman and Miner 1998). Different types of mindfulness practices have been shown to positively impact distinct state changes that are relevant to improving decision outcomes; breathing meditation and body scans seem to reduce mind chatter, while mindfulness practices focused on observing thoughts maximize individuals' capacity for meta-cognitive awareness (Dane et al. 2012). Investing time in the experiential practice of mindfulness, which cultivates body awareness (e.g., body scans), may be an efficient way to enhance the facility of turning inwards and, at the very least, familiarize individuals with sensations or feelings in the body they experience in different emotional states to aid their decision-making. We draw on these insights to propose:

Practice Proposition Four. Mindfulness practice might facilitate access to "Wu" and/or intuition during decision-making.

These four practice-related propositions help translate academic theorizing into real-world decision-making situations. Business schools and workplaces may benefit from implementing processes that enable their people to become aware of how their past, and near-past, experience informs their present interactions and that bring attention to their present and changing social and organizational space. Introducing journaling opportunities or short mindfulness practices (e.g., breath awareness, visualization exercises) into the classroom or office may help in this regard (Sadler-Smith and Burke 2009). Indeed, simply providing permission to pause and take a break may be enough to facilitate greater awareness of one's experience. 


\subsection{Method Contributions}

In addition to the above contributions to theory and practice, we suggest that this paper and the PDW on which it is founded make contributions to method. The benefits of diary and experience sampling methods (ESM) have been steadily heralded as a meaningful method to examine within-person variation over time while minimizing the bias embedded in retrospective accounts of experience. Deployment of micro diaries can become a significant research technique for bringing awareness to phenomenon that might otherwise go undetected during the decision-making process. Simply by asking the question, the researcher can direct the participant's attention to aspects of the decision-making process that might otherwise not be considered relevant (Burke and Sadler-Smith 2006). By posing questions to participants, micro diary or ESM accounts (Fisher and To 2012) can direct attention towards how the pressures of organizational life, the presence of other persons, or bodily sensations might impact decision-making in a relatively unobtrusive manner that does not significantly interrupt daily work-life. Applying such methods might provide real-time, context specific insights to add to the existing literature on emotion, mood states and decision-making behavior (Sinclair et al. 2010) that might otherwise go unnoticed. Other states relevant to decision-making processes, like the degree of, or changes in, felt pressure under VUCA conditions may also illuminate how the dynamism of individual experience informs decision-making. While others have made compelling arguments for the application of ESM in organizational behavior research, this method might aid individuals in becoming aware of subtle aspects of their experience beyond cognition and affect. We therefore propose the following:

Method Proposition One. Micro diaries interrupt unconscious processing and reveal personal in the moment experiences related to in-context decision-making that otherwise might go unnoticed.

In addition, we have wilfully spanned units and levels of analysis. Whereas other researchers may make these leaps unknowingly, we call attention to this aspect of our research and celebrate it. Our contention is that consciously making cross-level leaps provides a wealth of information for us to draw from, particularly because, in a social context, micro, meso, and macro levels are not independent. Physics shows that the micro is a fractal of the macro and vice versa; they are linked, nested, and fluid. Following scholars such as Gronn (2002) the social sciences community has paid more attention to the discipline of clarifying levels of analysis, nevertheless, we suggest a re-combination. Recognizing that sense making and deciding are inherently fluid, messy, and complex (Weick 1993) our research methods consciously acknowledge this, and for this reason we propose:

Method Proposition Two. Mixing units and levels of analysis mirrors the multi-level (micro, meso and meta) processes of decision-making and provides new insights.

\section{Conclusions and Future Directions}

Mindfulness, intuition, wisdom, organizational space, and social improvisation have provided the five perspectives through which this paper considered non-traditional approaches to decision-making. Each perspective has been held alongside the others to reveal areas of complementarity and to generate innovative insight that is integrative, neither reducing nor simplifying any one of these perspectives. From our review of the existing literature, our conjecture is that mindfulness may provide a gateway to intuition and wisdom. Similarly, organizational space may have a dampening or reinforcing effect on mindfulness; or a sense of space may act directly to support intuition and/or wisdom at individual and collective levels.

The researchers' initial intuitions on this topic were substantiated during a PDW at the 2016 Academy of Management where participants were asked to work in groups and make a decision concerning a picture puzzle. Micro diaries were used to interrupt the flow of decision-making to encourage participants to reflect on the minutiae of their changing thoughts, feelings, and bodily 
sensations throughout the experience. By collecting empirical data throughout this short group experience of deciding under conditions of uncertainty we sought to understand how each theoretical perspective might play out and interact with the others in practice.

The diaries reveal that physically stretching the body and that changing the physicality in the room affect somatic and affective states within, between and among individuals. Similarly, and equally important, internal thoughts and feelings contribute to a participant's state of mind, as does a lack of coffee! Through the micro diaries we also see the sheer volatility of state-how quickly it shifts; we see how very small things change mood and disposition-how this changes the nature of the contribution from each participant; we see evidence of socially constructed sense-making-how ambiguity is uncomfortable and individuals make diverse moves to reduce it, either consciously or unconsciously; and we see how impactful others can be on the creation of a setting in which all this happens. These observations have led us to put forth propositions to expand our understanding of decision-making as below (Table 6):

Table 6. Summary of propositions.

\begin{tabular}{|c|c|c|}
\hline Theory Contributions & Practice Contributions & Method Contributions \\
\hline $\begin{array}{l}\text { VUCA, previously solely a contextual } \\
\text { concern for organizations, is also an } \\
\text { experience of the ever-changing human } \\
\text { condition during decision-making. }\end{array}$ & $\begin{array}{l}\text { Internal, interpersonal, and collective } \\
\text { somatic, and affective states are carried } \\
\text { by individuals from one context to the } \\
\text { next, and decision-making is impacted } \\
\text { by these cumulative effects. }\end{array}$ & $\begin{array}{l}\text { Micro diaries interrupt } \\
\text { unconscious processing and reveal } \\
\text { personal lived-experiences related } \\
\text { to in-context decision-making. }\end{array}$ \\
\hline $\begin{array}{l}\text { VUCA exists inside an individual; in the } \\
\text { space between individuals; and it marks } \\
\text { the collective space within which a } \\
\text { decision is shaped. }\end{array}$ & $\begin{array}{l}\text { In a VUCA environment, small } \\
\text { modifications and details may have a } \\
\text { big effect on somatic and affective states, } \\
\text { and in turn on the decision outcome. }\end{array}$ & $\begin{array}{l}\text { Mixing units and levels of analysis } \\
\text { mirrors the multi-level } \\
\text { (micro, meso and meta) processes } \\
\text { of decision-making and provides } \\
\text { new insights. }\end{array}$ \\
\hline $\begin{array}{l}\text { VUCA- Internal, interpersonal, } \\
\text { and collective-is dynamic, and its } \\
\text { cumulative effects on decision-making } \\
\text { are in constant flux. }\end{array}$ & $\begin{array}{l}\text { Facilitators of decisions can unearth } \\
\text { diverse experiences of VUCA in the } \\
\text { interests of helping individuals to be } \\
\text { aware of the effect of specific or } \\
\text { cumulative states. }\end{array}$ & \\
\hline $\begin{array}{l}\text { Individuals may be consciously aware } \\
\text { of the effect of somatic and affective } \\
\text { states and if so, may use this awareness } \\
\text { as a further resource when deciding. }\end{array}$ & $\begin{array}{l}\text { Mindfulness practice might facilitate } \\
\text { access to "Wu" and/or intuition during } \\
\text { decision-making. }\end{array}$ & \\
\hline
\end{tabular}

Our intention has been to stimulate more fluid lines of enquiry in the research and theorizing of decision-making, particularly through multi-modal perspectives. The applications for future research are both plentiful and exciting, here we discuss several possibilities.

The four theory propositions offered in this paper very loosely overlay onto Figure 1 (the map of the research framework). Whilst these findings are helpful in confirming the authors' expectations of complexity and fluidity, it would be interesting to gather further empirical evidence specifically guided by Figure 1. Visual mapping of theoretical contributions allows for the spanning of different philosophies and different ontologies and has the potential to provide an even more comprehensive view of non-rational decision-making.

Bringing together the inter-relatedness of individuals, social context, and somatic phenomenon offers the potential to explore questions of how inter-relating bodies in space inform decision outcomes (Sinclair and Hamilton 2014; Maimone and Sinclair 2014). Of course, the varying levels of awareness of such aspects as the presence of others or sensations in our own bodies fluctuate. Thus, simply investigating varying levels of awareness presents another line of inquiry into what factors influence decision-making and how. In this respect, the impact of expertise must be acknowledged. While expertise has long been explored in the rational decision-making literature (Dane et al. 2012), and more recently under the umbrella of intuitive decision-making (Dane et al. 2012), how expertise relates to improvisation (Batista and Cunha 2008) and accordingly, how such expertise might impact 
decision-making remains under investigated. Beyond differences in abilities to improvise, differences in abilities in other areas such as detection of one's own bodily sensations or awareness of one's general social space may shed light on the decision-making process.

Another promising area of research that stems from our multi-modal focus involves collecting data from multiple perspectives (Patel 2016). In our PDW, we attempted to capture the experience of the participants and the facilitators. While it is beyond the scope of our paper to fully analyze these experiences, there is an opportunity to gain a deeper understanding of the decision-making process by considering multiple perspectives, how they converge and interact to influence social improvisation. Collecting data that captures multiple perspectives might reveal how decision outcomes are impacted by different interpretations of a scenario, power or status differences in players, and how individual experiences and group dynamics interact.

More specifically, future research on the distinction and integration between the Eastern and the Western view might consider the importance of unlearning. In the realm of "Wu", it was known as "learned ignorance" (Chia and Holt 2007; cf. (Weick 2007). Lao Tse (571-471 BC), the founding father of Taoism, pointed out that in the pursuit of knowledge something is gained each day, while in the pursuit of wisdom something is lost each day. Only when nothing is left to lose anymore is everything gained altogether and wisdom is created. In this sense, "Wu" has the potential to shed light on the link between unlearning and learning, and how it can help us consider other information or processes when making decisions. Further, the principle of "Wu" would suggest that unlearning is a necessary antecedent to exploratory learning and thence to System 3 thinking ( $\mathrm{Li} 2014$ ).

Although " $\mathrm{Wu}$ " is considered an individual faculty, there may be a similar phenomenon available socially. Scholarship concerning heedful inter-relating is already strong (see for example Weick and Roberts (1993)) but this line of enquiry mostly considers issues around how the collective mind is formed. To date, so far as we know, there is little scholarship on the mechanism by which individuals "give up" their individually held schemata to more fully contribute to the social. A prerequisite for the smooth functioning of a group process appears to be an ability to accept conflicting information and overcome personal doubts. As DeDeo (2014) suggests "group minds" are mental properties that differ from the individual minds out of which they are constructed. It is likely that future studies in this area will draw on group dynamics, improvisation, and ethnographic approaches.

In this paper, we set out to uncover hidden aspects of decision-making using five different perspectives. A small group experience reveals that decision-making is an innately human practice with all the fallibilities and foibles of humanness; as such, it cannot be categorized as rational or non-rational but instead must be considered in a holistic way. We suggest that the above five streams of theorizing can be useful without being collated and reduced. Further, we suggest that scholarship on decision-making is better served by considering both rational and non-rational approaches as interlocking human systems where somatic and affective states at several levels are in flux. We call for more research and theorizing to test and build upon the emerging process ontology we have described herein. Further research in this domain stands to benefit people in organizations tasked with making decisions in an increasingly VUCA world. As organizations begin to have the power and might of small nations (GPF 2010), their decisions become critical to the future of our world. How those decisions get made in the context of internal and external VUCA has never been more vital.

Acknowledgments: The authors would like to express their gratitude to Peter Ping Li and Fabrizio Maimone for contributing to the ideas that led to the creation of this article.

Author Contributions: All authors were involved in the research design, data collection and analysis of the data. The first three authors contributed equally to the writing of the paper. All authors read, edited, and approved the final manuscript.

Conflicts of Interest: The authors declare no conflict of interest. 


\section{Appendix A}

Below are three examples of the picture riddles used during the decision-making experience, alongside a brief explanation of their respective purposes. These photographs were presented to the participating groups at the beginning of the exercise. Each group was tasked with making joint decisions about what each of the objects' purpose was.

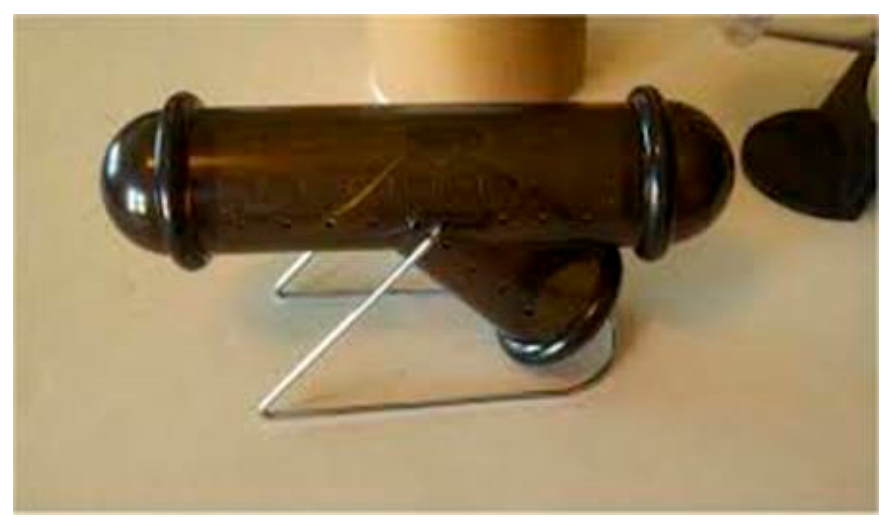

Figure A1. Mouse trap \#1.

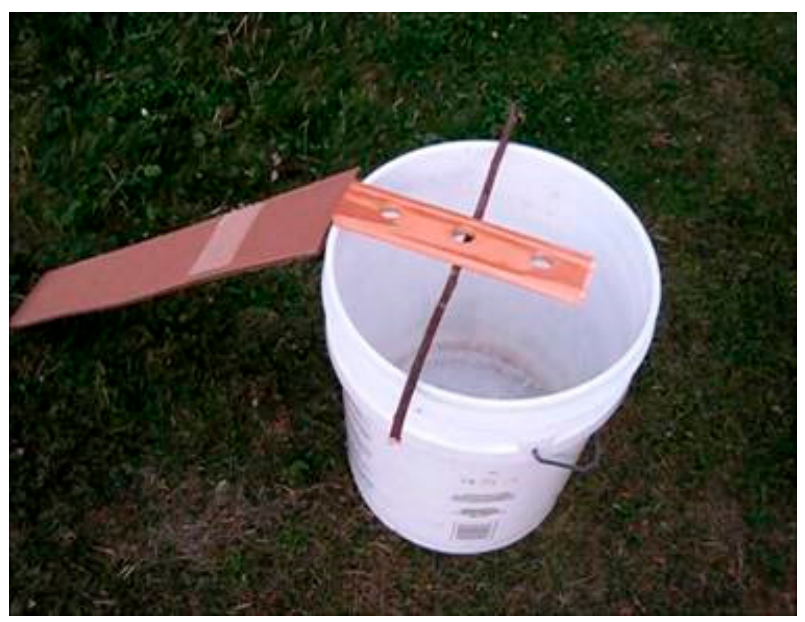

Figure A2. Mouse trap \#2.

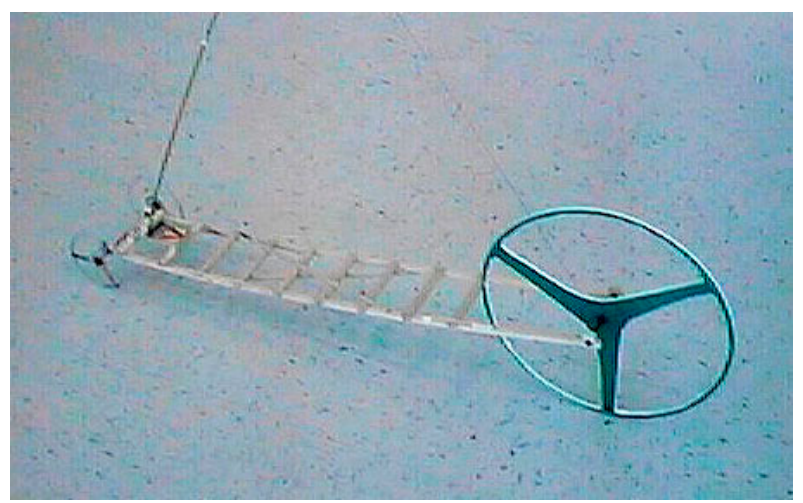

Figure A3. Mouse-propelled transport. 


\section{References}

Allison, Graham T. 1969. Conceptual Models and the Cuban Missile Crisis. The American Political Science Review LXIII 63: 689-717. [CrossRef]

Amabile, Teresa A., and Mukti Khaire. 2008. Creativity and the Role of the Leader. Harvard Business Review 86: 142.

Baas, Matthijs, Barbara Nevicka, and Femke S. Ten Velden. 2014. Specific Mindfulness Skills Differentially Predict Creative Performance. Personality E Social Psychology Bulletin 26: 1-15.

Batista, Maria da Graça Câmara, and Miguel Pina Cunha. 2008. Improvising at work: The differences between experts and novices. International Journal of Organization Theory and Behavior 11: 295-315.

Baylor, Amy L. 2001. A U-Shaped Model for the Development of Intuition by Level of Expertise. New Ideas in Psychology 19: 237-44. [CrossRef]

Bechara, Antoine. 2004. The Role of Emotion in Decision making: Evidence from Neurological Patients with Orbitofrontal Damage. Brain and Cognition 55: 30-40. [CrossRef] [PubMed]

Begley, Sharon, and Richard J. Davidson. 2012. The Emotional Life of Your Brain: How Its Unique Patterns Affect the Way You Think, Feel, and Live-and How You Can Change Them. London: Hachette UK.

Behling, Orlando, and Norman L. Eckel. 1991. Making Sense out of Intuition. Academy of Management 5: 46-54. [CrossRef]

Bradley, Raymond Trevor. 2011. Resolving the enigma of nonlocal intuition: A quantum-holographic approach. In Handbook of Intuition Research. Edited by Marta Sinclair. Cheltenham: Edward Elgar Publishers, pp. 197-213.

Brown, Kirk Warren, and Richard M. Ryan. 2003. The Benefits of Being Present: Mindfulness and Its Role in Psychological Well-Being. Journal of Personality and Social Psychology 84: 822-48. [CrossRef] [PubMed]

Burke, Lisa A., and Eugene Sadler-Smith. 2006. Instructor Intuition in the Educational Setting. Academy of Management Learning and Education 5: 169-81. [CrossRef]

Cappon, Daniel. 1993. The anatomy of intuition. Psychology Today 26: 40-49.

Chia, Robert, and Robin Holt. 2007. Wisdom as learned ignorance: Integrating East-West perspectives. In Handbook of Managerial and Organizational Wisdom. Edited by Eric H. Kessler and James R. Bailey. Sage: Thousand Oaks, pp. 505-26.

Coget, Jean-Francois, and Eugene Keller. 2010. The critical decision vortex: Lessons from the emergency room. Journal of Management Inquiry 19: 56-67. [CrossRef]

Connelly, Shane, and Janaki Gooty. 2015. Leading with Emotion: An Overview of the Special Issue on Leadership and Emotions. The Leadership Quarterly 26: 485-88. [CrossRef]

Crevani, Lucia, Monica Lindgren, and Johann Packendorff. 2010. Leadership, Not Leaders: On the Study of Leadership as Practices and Interactions. Scandinavian Journal of Management 26: 77-86. [CrossRef]

Crossan, Mary, and Marc Sorrenti. 1997. Making Sense of Improvisation. Advances in Strategic Management 14: $155-80$.

Crossan, Mary M., Henry W. Lane, and Roderick E. White. 1999. An organizational learning framework: From intuition to institution. Academy of Management Review 24: 522-37. [CrossRef]

Damasio, Antonio R. 1994. Descartes' Error: Emotion, Rationality and the Human Brain. New York: Putnam.

Dane, Erik. 2011. Capturing intuitions 'in flight': Observations from research on attention and mindfulness. In Handbook of Intuition Research. Edited by Marta Sinclair. Cheltenham: Edward Elgar, pp. 217-26.

Dane, Erik, and Michael G. Pratt. 2007. Exploring Intuition and Its Role in Managerial Decision Making. Academy of Management Review 32: 33-54. [CrossRef]

Dane, Erik, Kevin W. Rockmann, and Michael G. Pratt. 2012. When should I trust my gut? Linking domain expertise to intuitive decision making effectiveness. Organizational Behavior and Human Decision Processes 119: 187-94. [CrossRef]

DeDeo, Simon. 2014. Group Minds and the Case of Wikipedia. Human Computation 1: 5-29. [CrossRef]

Deloitte. 2016. There's No Place like Phone-Global Mobile Consumer Survey 2016. Available online: https:/ / www.deloitte.co.uk/mobileuk/assets/pdf/Deloitte-Mobile-Consumer-2016-There-is-noplace-like-phone.pdf (accessed on 28 February 2017).

Desbordes, Gaëlle, Lobsang T. Negi, Thaddeus W. W. Pace, B. Alan Wallace, Charles L. Raison, and Eric L. Schwartz. 2012. Effects of mindful-attention and compassion meditation training on amygdala response to emotional stimuli in an ordinary, non-meditative state. Frontiers in Human Neuroscience 6: 1-15. [CrossRef] [PubMed] 
Dijksterhuis, Albert Jan. 2004. Think different: The merits of unconscious thought in preference development and decision making. Journal of Personality and Social Psychology 87: 586-98. [CrossRef] [PubMed]

Dörfler, Viktor, and Fran Ackermann. 2012. Understanding Intuition: The Case for Two Forms of Intuition. Management Learning 43: 545-64. [CrossRef]

Dreyfus, Stuart. E. 2014. System 0: The overlooked explanation of expert intuition. In Handbook of Research Methods on Intuition. Edited by Marta Sinclair. Cheltenham: Edward Elgar, pp. 25-27.

Eisenhardt, Kathleen. 1997. Strategic Decisions and All That Jazz. Business Strategy Review 8: 1-3. [CrossRef]

Eisenhardt, Kathleen M., and Mark J. Zbaracki. 1992. Strategic Decision Making. Strategic Management Journal 13: 17-37. [CrossRef]

Epstein, Seymour. 1990. Cognitive Experiential Self-Theory. In Handbook of Personality: Theory and Research. Edited by Lawrence A. Pervin. New York: Guilford, pp. 165-92.

Evans, Jonathan St B. T. 2008. Dual-Processing Accounts of Reasoning, Judgment, and Social Cognition. Annual Review of Psychology 59: 255-78. [CrossRef] [PubMed]

Faulkner, Xristine, and Fintan Culwin. 2005. When Fingers Do the Talking: A Study of Text Messaging. Interacting with Computers 17: 167-85. [CrossRef]

Fiol, C. Marlene, and Edward J. O'Connor. 2003. Waking Up! Mindfulness in the Face of Bandwagons. Academy of Management Review 28: 54-70. [CrossRef]

Fisher, Cynthia D., and March L. To. 2012. Using experience sampling methodology in organizational behavior. Journal of Organizational Behavior 33: 865-77. [CrossRef]

Fraser. 2012. The Third Space. Melbourne: Random House.

Garland, Eric L., Susan A. Gaylord, and Barbara L. Fredrickson. 2011. Positive reappraisal mediates the stress-reductive effects of mindfulness: An upward spiral process. Mindfulness 2: 59-67. [CrossRef]

Gendlin, Eugene T. 1995. Crossing and dipping: Some terms for approaching the interface between natural understanding and logical formulation. Minds and Machines 5: 547-60. [CrossRef]

Christopher K. Germer, and Ronald D. Siegel, eds. 2012. Wisdom and Compassion in Psychotherapy: Deepening Mindfulness in Clinical Practice. New York: Guilford Press.

Goldberg, Philip. 1983. The Intuitive Edge: Understanding Intuition and Applying It in Everyday Life. Los Angeles: Jeremy P. Tarcher.

GPF. 2010. Comparison of the World's 25 Largest Corporations with the GDP of Selected Countries. Available online: https:/ / www.globalpolicy.org/component/content/article/150-general/50950-comparison-of-theworlds-25-largest-corporations-with-the-gdp-of-selected-countries.html (accessed on 11 July 2017).

Gronn, Peter. 2002. Distributed Leadership as a Unit of Analysis. The Leadership Quarterly 13: 423-51. [CrossRef] Gunaratana, Ven Henepola. 2009. Mindfulness in Plain English. Boston: Wisdom Publications.

Hafenbrack, Andrew C., Zoe Kinias, and Sigal G. Barsade. 2013. Debiasing the Mind through Meditation Mindfulness and the Sunk-Cost Bias. Psychological Science 25: 369-76. [CrossRef] [PubMed]

Haidt, Jonathan. 2001. The Emotional Dog and Its Rational Tail: A Social Intuitionist Approach to Moral Judgment. Psychological Review 108: 814-34. [CrossRef] [PubMed]

Hernes, Tor, ed. 2007. Understanding Organization as Process: Theory for a Tangled World. Organization Studies (01708406). London: Routledge.

Hicks, Stiehm Judith, and W. Townsend Nicholas. 2002. The US Army War College: Military Education in a Democracy. Philadelphia: Temple University Press.

Hodgkinson, Gerard P, Janice Langan-Fox, and Eugene Sadler-Smith. 2008. Intuition: A Fundamental Bridging Construct in the Behavioral Sciences. British Journal of Psychology 99: 1-27. [CrossRef] [PubMed]

Isenberg, Daniel J. 1984. How Senior Managers Think. Harvard Business Review 62: 81-90.

Kabat-Zinn, Jon. 2005. Full Catastrophe Living: Using the Wisdom of Your Body and Mind to Face Stress, Pain, and Illness. Brighton: Delta, First published in 1990.

Kabat-Zinn, Jon. 2013. Full Catastrophe Living: How to Cope with Stress, Pain and Illness Using Mindfulness Meditation, rev. ed. London: Hachette UK.

Kahneman, Daniel. 2011. Thinking, Fast and Slow. New York: Farrar, Straus and Giroux.

Kahneman, Daniel, and Gary Klein. 2009. Conditions for Intuitive Expertise: A Failure to Disagree. The American Psychologist 64: 515-26. [CrossRef] [PubMed]

Kahneman, Daniel, Paul Slovic, and Amos Tversky. 1982. Judgment under Uncertainty: Heuristics and Biases. Cambridge: Cambridge University Press. 
Kenworthy, Amy L. 2014. From the Editors: Lessons Learned From Dance-Cross-Training as a Tool for Moving Forward in Our Discipline. Academy of Management Leaning and Education 13: 151-53. [CrossRef]

Klein, Gary A. 1998. Sources of Power: How People Make Decisions. Cambridge: The MIT Press.

Kornberger, Martin, and Stewart R. Clegg. 2004. Bringing Space Back in: Organizing the Generative Building. Organization Studies 25: 1095-114. [CrossRef]

Lane, Henry W., and Martha Maznevski. 2014. International Management Behavior: Global and Sustainable Leadership. New York: John Wiley \& Sons.

Langan-Fox, Janice, and Vedran Vranic. 2011. Life, Death, and Intuition in Critical Occupations. In Handbook of Intuition Research. Cheltenham: Edward Elgar, pp. 111-121.

Langer, Ellen J. 1992. Matters of Mind: Mindfulness/Mindlessness in Perspective. Consciousness and Cognition 1: 289-305. [CrossRef]

Langer, Ellen J., and Mihnea Moldoveanu. 2000. The construct of mindfulness. Journal of Social Issues 56: 1-9. [CrossRef]

Langley, Ann, Henry Mintzberg, Patricia Pitcher, Elizabeth Posada, and Jan Saint-Macary. 1995. Opening up Decision Making: The View from the Black Stool. Organization Science 6: 260-79. [CrossRef]

Lefebvre, Henri. 1991. The Production of Space. Oxford: Blackwell Publishing Ltd.

Leybourne, Stephen, and Eugene Sadler-Smith. 2006. The Role of Intuition and Improvisation in Project Management. International Journal of Project Management 24: 483-92. [CrossRef]

Li, Peter Ping. 2012. Exploring the unique roles of trust and play in private creativity: From the complexity-ambiguity-metaphor link to the trust-play-creativity link. Journal of Trust Research 2: 71-97. [CrossRef]

Li, Peter Ping. 2014. 3 Toward the geocentric framework of intuition: The yin- yang balancing between the eastern and western perspectives on intuition. In Handbook of Research Methods on Intuition. Edited by Marta Sinclair. Cheltenham: Edward Elgar, pp. 28-41.

Lieberman, Matthew D. 2000. Intuition a social cognitive neuroscience approach. Psychological Bulletin 126: 109-37. [CrossRef] [PubMed]

Lieberman, Matthew D. 2007. The X-and C-systems: Integrating biological and psychological explanations of social behavior. In Fundamentals of Social Neuroscience. Edited by Eddie Harmon-Jones and P. Winkelman. New York: Guilford, pp. 290-315.

Lieberman, Matthew D., Johanna M. Jarcho, and Ajay B. Satpute. 2004. Attitudes and Social Cognition Evidence-Based and Intuition-Based Self-Knowledge: An fMRI Study. Journal of Personality and Social Psychology 87: 421-35. [CrossRef] [PubMed]

Lieberman, Matthew D., Naomi I. Eisenberger, Molly J. Crockett, Sabrina M. Tom, Jennifer H. Pfeifer, and Baldwin M. Way. 2007. Putting feelings into words: Affect labeling disrupts amygdala activity in response to affective stimuli: Research article. Psychological Science 18: 421-28. [CrossRef] [PubMed]

Maimone, Fabrizio, and Marta Sinclair. 2014. Dancing in the Dark: Creativity, Knowledge Creation and (Emergent) Organizational Change. Journal of Organizational Change Management 27: 344-61. [CrossRef]

March, James G., and Herbert A. Simon. 1993. Organizations revisited. Industrial and Corporate Change 2: $299-316$. [CrossRef]

Meyer, Alan, Peter J. Frost, and Karl E. Weick. 1998. The organization science jazz festival: Improvisation as a metaphor for organizing-overture. Organization Science 9: 540-42. [CrossRef]

Monsay, Evelyn H. 1997. Intuition in the Development of Scientific Theory and Practice. In Intuition: The inside Story. New York: Routledge, pp. 103-20.

Moorman, Christine, and Anne. S. Miner. 1998. Organizational Improvisation and Organizational Memory. Academy of Management Review 23: 698-723. [CrossRef]

Morgeson, Frederick P., and David A. Hofmann. 1999. The Structure and Function of Collective Constructs: Implications for Multilevel Research and Theory Development. Academy of Management Review 24: 249-65.

Mrazek, Michael D., Michael S. Franklin, Dawa Tarchin Phillips, Benjamin Baird, and Jonathan W. Schooler. 2013. Mindfulness Training Improves Working Memory Capacity and GRE Performance While Reducing Mind Wandering. Psychological Science 24: 776-81. [CrossRef] [PubMed]

Nonaka, Ikujiro, and Noboru Konno. 1998. The Concept of 'Ba': Building a foundation for knowledge creation. California Management Review 40: 40-54. [CrossRef]

Nonaka, Ikujiro, and Hirotaka Takeuchi. 1991. The Knowledge-Creating Company. Oxford: Oxford University Press. Nonaka, Ikujiro, and Hirotaka Takeuchi. 1995. The Knowledge-Creating Company. Oxford: Oxford University Press. 
Nonaka, Ikujiro, Georg Von Krogh, and Sven Voelpel. 2006. Organizational Knowledge Creation Theory: Evolutionary Paths and Future Advances. Organization Studies 27: 1179-208. [CrossRef]

Ostafin, Brian D., and Kyle T. Kassman. 2012. Stepping out of History: Mindfulness Improves Insight Problem Solving. Consciousness and Cognition 21: 1031-36. [CrossRef] [PubMed]

Oullier, Olivier, and Frédéric Basso. 2010. Embodied Economics: How Bodily Information Shapes the Social Coordination Dynamics of Decision-Making. Philosophical Transactions of the Royal Society of London. Series B, Biological Sciences 365: 291-301. [CrossRef] [PubMed]

Parikh, Jagdish, Franz-Friedrich Neubauer, and Alden G. Lank. 1994. Intuition: The New Frontier of Management. Oxford: Blackwell.

Patel, Taran. 2016. Promoting Multi-Paradigmatic Cultural Research in International Business Literature. Journal of Organizational Change Management 29: 599-629. [CrossRef]

Peper, Erik, and I-Mei Lin. 2012. Increase or decrease depression-How body postures influence your energy level. Biofeedback 40: 126-30. [CrossRef]

Petitmengin, Claire. 2006. Describing One's Subjective Experience in the Second Person: An Interview Method for the Science of Consciousness. Phenomenology and the Cognitive Sciences 5: 229-69. [CrossRef]

Raelin, Joseph A. 2007. Toward an Epistemology of Practice. Academy of Management Learning and Education 6: 495-519. [CrossRef]

Rinpoche, Geshe Thupten Jinpa. 2003. Lighting the Path: The Dalai Lama Teaches on Wisdom and Compassion. Melbourne: Lothian Books.

Sadler-Smith, Eugene. 2016. 'What Happens When You Intuit?' Understanding Human Resource Practitioners' Subjective Experience of Intuition through a Novel Linguistic Method. Human Relations 69: 1069-93. [CrossRef]

Sadler-Smith, Eugene, and Lisa Burke. 2009. Fostering Intuition in Management Education: Activities and Resources. Journal of Management Education 33: 239-62. [CrossRef]

Salk, Jonas. 1983. Anatomy of Reality. New York: Columbia University.

Santorelli, Saki F. 2011. 'Enjoy Your Death': Leadership Lessons Forged in the Crucible of Organizational Death and Rebirth Infused with Mindfulness and Mastery. Contemporary Buddhism 12: 199-217. [CrossRef]

Shevrin, Howard, Jaak Panksepp, Linda A. W. Brakel, and Michael Snodgrass. 2012. Subliminal affect valence words change conscious mood potency but not valence: Is this evidence for unconscious valence affect? Brain Sciences 2: 504-22. [CrossRef] [PubMed]

Shotter, John, and Haridimos Tsoukas. 2014. In Search of phronesis: Leadership and the art of judgment. Academy of Management Learning and Education 13: 224-43. [CrossRef]

Simon, Herbert Alexander. 1987. Making Management Decisions: The Role of Intuition and Emotion. The Academy of Management Executive, 57-64. [CrossRef]

Sinclair, Marta. 2010. Misconceptions about Intuition. Psychological Inquiry 21: 378-86. [CrossRef]

Sinclair, Amanda. 2016. Leading Mindfully: How to Focus on What Matters, Influence for Good, and Enjoy Leadership More. Sydney: Allen \& Unwin.

Sinclair, Marta, and Neal M. Ashkanasy. 2005. Intuition: Myth or a Decision making Tool? Management Learning 36: 353-70. [CrossRef]

Sinclair, Marta, and Alysia Hamilton. 2014. 15 Mapping group intuitions. In Handbook of Research Methods on Intuition. Cheltenham: Edward Elgar Publishing, pp. 199-216.

Sinclair, Marta, and Carl Sinclair. 2009. Improving hotel efficiency through integration of service and project management cultures. International Journal of Hospitality $\mathcal{E}$ Tourism 10: 344-60.

Sinclair, Marta, Neal M. Ashkanasy, and Prithviraj Chattopadhyay. 2010. Affective antecedents of intuitive decision making. Journal of Management \& Organization 16: 382-98.

Stanovich, Keith. E., and Richard F. West. 2000. Advancing the Rationality Debate. Behavioral and Brain Sciences 23: 701-17. [CrossRef]

Sutcliffe, Kathleen M., Timothy J. Vogus, and Erik Dane. 2016. Mindfulness in Organizations: A Cross-Level Review. Annual Review of Organizational Psychology and Organizational Behavior 3: 1-57. [CrossRef]

Teerikangas, Satu, and Liisa Välikangas. 2014. Exploring the dynamic of evoking intuition. In Handbook of Research Methods on Intuition. Edited by Marta Sinclair. Cheltenham: Edward Elgar, pp. 72-87.

Tombs, Alastair, and Janet R. McColl-Kennedy. 2003. Social-servicescape conceptual model. Marketing Theory 3: 447-75. [CrossRef] 
Tombs, Alastair G., and Janet R. McColl-Kennedy. 2010. Social and spatial influence of customers on other customers in the social-servicescape. Australasian Marketing Journal 18: 120-31. [CrossRef]

Turley, Lou W., and Ronald E. Milliman. 2000. Atmospheric Effects on Shopping Behavior: A Review of the Empirical Evidence. Journal of Business Research 49: 193-211. [CrossRef]

Tversky, Amos, and Daniel Kahneman. 1985. The framing of decisions and the psychology of choice. In Environmental Impact Assessment, Technology Assessment, and Risk Analysis. Berlin/Heidelberg, Germany: Springer, pp. 107-29.

Vaughan, Frances E. 1979. Awakening Intuition. New York: Doubleday/Anchor Press.

Von Krogh, Georg, Ikujiro Nonaka, and Lise Rechsteiner. 2012. Leadership in Organizational Knowledge Creation: A Review and Framework. Journal of Management Studies 49: 240-77. [CrossRef]

Wally, Stefan, and J. Robert Baum. 1994. Personal and Structural Determinants of the Pace of Strategic Decision Making. Academy of Management Journal 37: 932-56. [CrossRef]

Wegner, Daniel M. 1987. Transactive Memory: A Contemporary Analysis of the Group Mind. In Theories of Group Behavior. Edited by Brian Mullen and George R. Goethais. New York: Springer, pp. 185-208.

Weick, Karl E. 1993. The collapse of sensemaking in organizations: The Mann Gulch disaster. Administrative Science Quarterly 38: 628-52. [CrossRef]

Weick, Karl E. 1998. Improvisation as a Mindset for Organizational Analysis. Organization Science 9: 543-55. [CrossRef]

Weick, Karl E. 2007. Foreword. In Handbook of Organizational and Managerial Wisdom. Thousand Oaks: Sage.

Weick, Karl E., and Karlene H. Roberts. 1993. Collective mind in organizations: Heedful interrelating on flight decks. Administrative Science Quarterly 38: 357-81. [CrossRef]

Yeung, Henry Wai-chung. 2005a. Organizational Space: A New Frontier in International Business Strategy? Critical Perspectives on International Business 1: 219-40. [CrossRef]

Yeung, Henry Wai-Chung. 2005b. The firm as social networks: An organisational perspective. Growth and Change 36: 307-28. [CrossRef]

(C) 2017 by the authors. Licensee MDPI, Basel, Switzerland. This article is an open access article distributed under the terms and conditions of the Creative Commons Attribution (CC BY) license (http://creativecommons.org/licenses/by/4.0/). 